\title{
Le massif forestier de Mervent-Vouvant (Vendée) de la Protohistoire à nos jours : premiers éléments d'une enquête archéologique et archéogéographique.
}

\author{
The forest massif of Mervent-Vouvant (Vendée) from Protohistory to the \\ present day: first elements of an archaeological and archaeogeographical
}

survey.

\author{
Olivier Nillesse ${ }^{1}$, Magali Watteaux ${ }^{2}$ \\ ${ }^{1}$ ingénieur de recherche, Inrap, olivier.nillesse@inrap.fr \\ ${ }^{2}$ MCF, université Rennes 2, magaliwatteaux@yahoo.fr
}

RÉSUMÉ. L'article rend compte des recherches conduites dans le cadre d'un Projet collectif de recherche sur le massif forestier de Mervent-Vouvant en Vendée depuis 2018 à la suite d'une acquisition LiDAR. Cette dernière a permis de renouveler et compléter substantiellement la carte archéologique de cette forêt et d'esquisser certaines pistes de travail. D'une recherche d'abord axée sur la problématique des habitats fortifiés de hauteur protohistoriques - en raison de la fouille de deux remparts du Hallstatt D3 à Mervent -, le projet a évolué vers une étude diachronique de l'ensemble du massif du fait de la masse de données attribuables aux autres périodes, en particulier médiévale et moderne. Les données LiDAR se révèlent être une source extrêmement riche d'informations, qu'il reste à analyser plus avant en croisant les apports de l'archéologie, de la géoarchéologie, de l'archéogéographie et de l'histoire.

ABSTRACT. The paper presents research carried out as part of a Collective Research Project on the Mervent-Vouvant forest in Vendée since 2018 following LiDAR acquisition. The latter made possible to substantially renew and complete the archaeological knowledge of this forest and to outline some ways of research. From research initially focused on the problem of fortified protohistoric habitats - because of the excavation of a fortified enclosure from Hallstatt D3 in the village of Mervent - the project has evolved into a diachronic study of the whole of the forest due to the mass of data attributable to other periods, in particular medieval and modern. LiDAR data turns out to be an extremely rich source of information, which remains to be analyzed further by combining the contributions of archeology, geoarchaeology, archaeogeography and history.

MOTS-CLÉS. forêt de Mervent, Vendée, archéogéographie, sites fortifiés de hauteurs.

KEYWORDS. forest of Mervent, Vendée, archaeogeography, fortified sites.

En 2018, un Projet collectif de recherche (PCR) sur l'histoire du massif forestier de MerventVouvant ${ }^{1}$ situé au sud-est de la Vendée a été lancé ${ }^{2}$ afin de faire le point sur deux siècles de recherches archéologiques, de prolonger des fouilles récentes sur le bourg de Mervent et d'exploiter une couverture LiDAR réalisée l'année précédente (fig. 1) (Nillesse dir. 2018). Ce projet de recherche fait suite à une série de fouilles préventives qui ont mis au jour un habitat de hauteur, daté du Hallstatt D3 (vers 500-450 av. J.-C.), associé à deux remparts dits du Chêne Tord et du Bourg (fig. 2), mais dont les résultats n'avaient pas permis de déterminer clairement les activités économiques des habitants (Nillesse et al. 2014 et 2017). L'objectif principal du PCR fut donc de comprendre la nature des ressources exploitées par les résidents de Mervent et de localiser leurs activités hors de l'agglomération. Les premières pistes envisagées ont concerné l'extraction et la réduction de métaux. Mervent étant situé dans un massif primaire, Guillaume Saint-Didier (2017) a fait l'hypothèse d'une activité de réduction du minerai de fer dès la Protohistoire dans ce massif. L'autre axe de recherche

\footnotetext{
${ }^{1}$ Anciennement la forêt fut appelée "forêt royale de Vouvant » puis «forêt impériale de Vouvant » avant de prendre son nom actuel en 1965 lors de la création de l'Office national des forêts.

${ }^{2}$ Ce Projet collectif de recherche a bénéficié, outre la participation des quelques chercheurs extérieurs à l'Inrap mentionnés dans le présent article, d'un budget alloué par la DRAC des Pays de la Loire de $1000 €$ et d'un Projet d'action scientifique (50 jours attribués) soutenu par l'Inrap. 
alors défini concernait l'organisation de ce territoire aujourd'hui forestier, en particulier les relations éventuellement entretenues entre les différents sites de hauteur reconnus dans ce secteur (Sauvaget, Le Saint-Luc, Berneveau, Les Rouillères), Mervent semblant être le plus important d'entre eux (fig. 3).

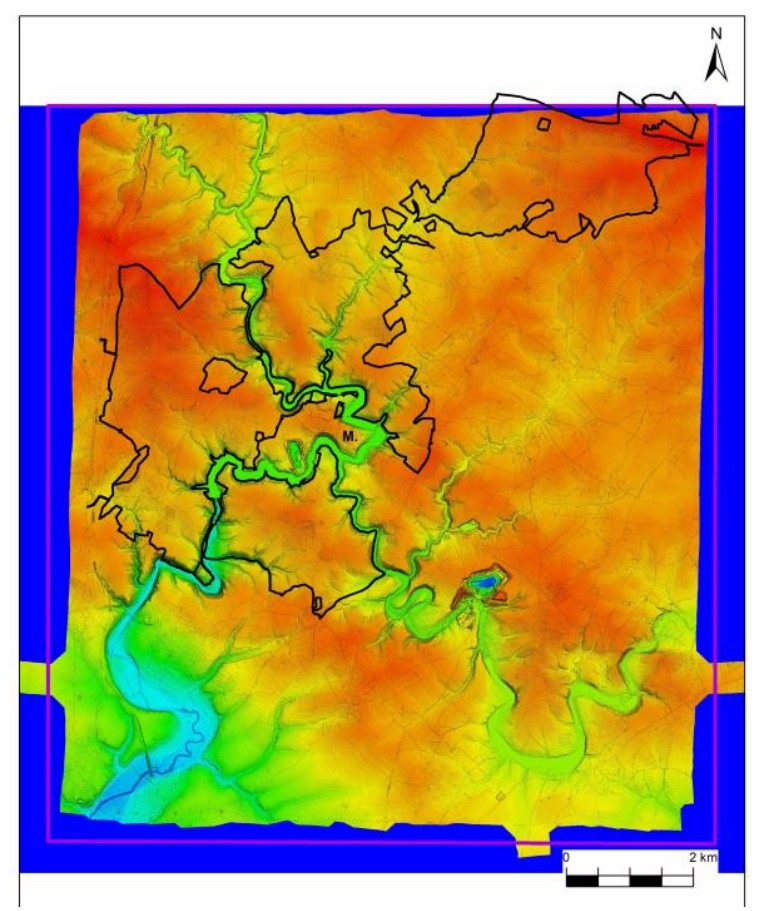

Fig. 1. MNT élaboré à partir des points classés "Sol» dans les données LiDAR acquises en 2017. Les limites de la forêt domaniale sont figurées en trait noir. $M=$ Mervent. Source : MNT/LiDAR et données de l'ONF, relevés : J.-M. Bryand, F. Melec, O. Nillesse.
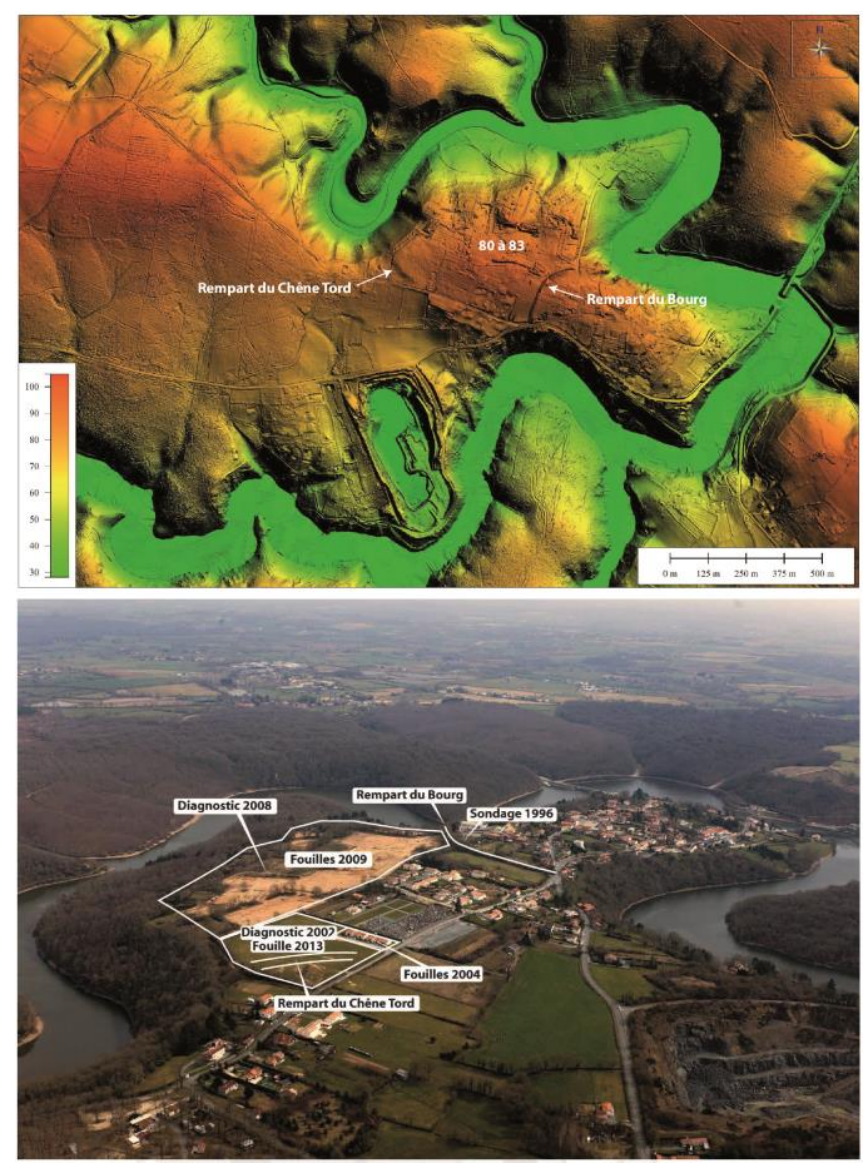

Fig. 2. Interventions archéologiques préventives sur le plateau de Mervent. Source : MNT/LiDAR, Nillesse et al. 2014, relevés : J.-M. Bryand, F. Melec, O. Nillesse. 


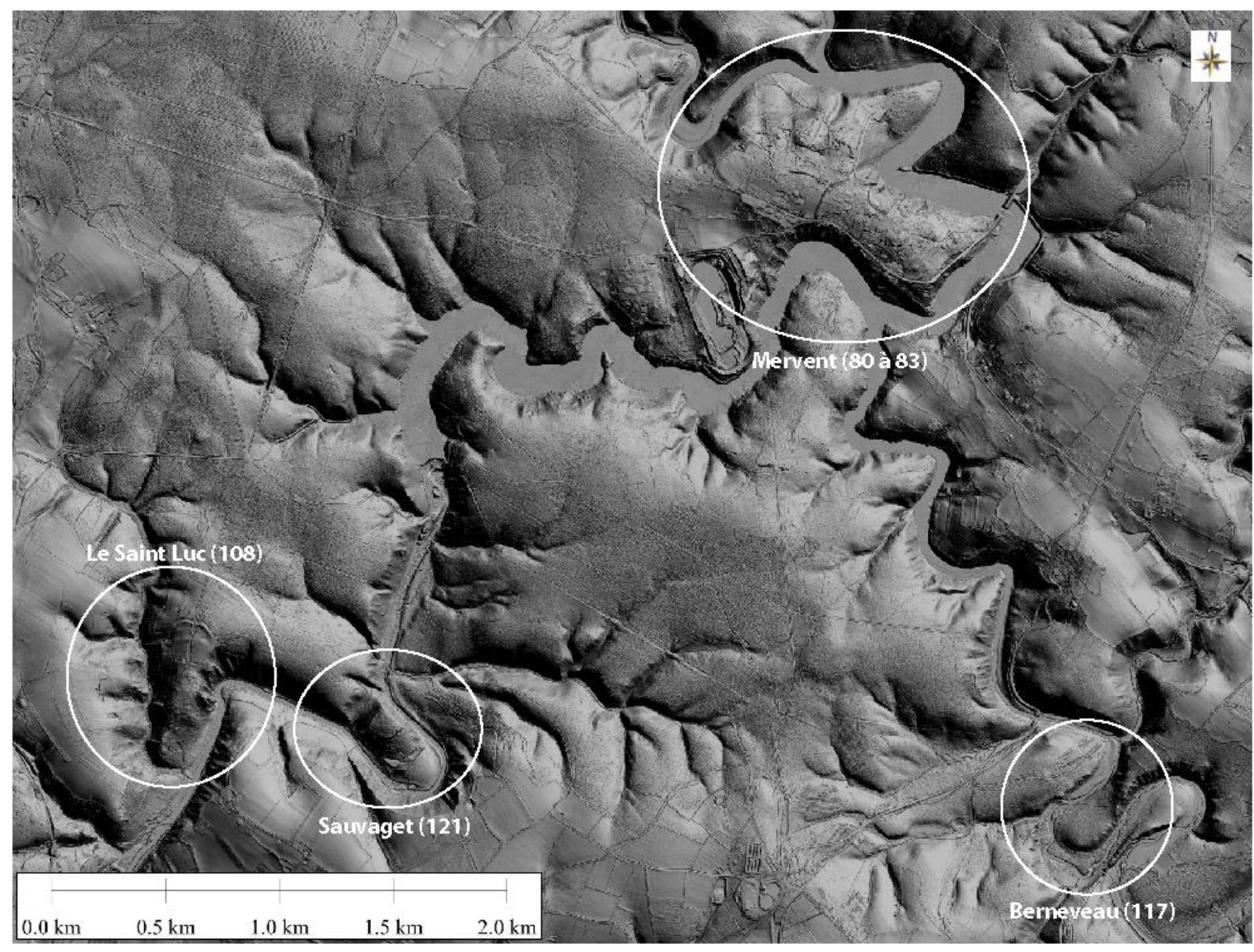

Fig. 3. Sites de hauteur présentant des éléments de fortification. Source : MNT/LiDAR, relevés : J.-M. Bryand, F. Melec, O. Nillesse.

Ces ambitions reposaient sur un lever LiDAR réalisé sur 9300 hectares qui a permis de révéler des centaines d'indices archéologiques, de toutes natures, et de faire évoluer les axes de recherche précités. Le champ d'intérêt du PCR s'est ainsi progressivement déplacé d'une entrée chronologique et historique - celle de la compréhension de sites fortifiés supposés ou non protohistoriques - à une entrée diachronique et géohistorique, ouvrant sur l'analyse d'un espace et de son histoire sur la très longue durée, couplant des lectures archéologique, historique et archéogéographique. Le titre initial du PCR, «Recherches sur l'occupation du massif de Mervent (Vendée) et ses habitats fortifiés », a ainsi été reformulé comme suit: «Les occupations du Massif de Mervent, étude diachronique et approche archéogéographique ». Ce sont les premiers résultats et surtout les perspectives de recherche de cette enquête balbutiante que nous présentons ici.

\section{Cadre géographique, documentation et données exploitées}

Le massif forestier de Mervent-Vouvant est le plus grand du département vendéen avec ses 5881 ha étendus sur neuf communes au nord de la capitale historique du Bas-Poitou, Fontenay-le-Comte (fig. 4). Il est partiellement géré, pour la partie domaniale (2 $518 \mathrm{ha}$ ), par l'Office national des forêts $(\mathrm{ONF})^{3}$, et par des propriétaires privés pour le reste. Propriété de différents seigneurs depuis le $\mathrm{XI}^{\mathrm{e}}$ siècle au moins, la forêt de Mervent est incorporée à la couronne en 1694, qui la donne en apanage au comte d'Artois (Canaud 2018). À partir de la Révolution, la partie royale de cette forêt devient propriété de l'État (forêt domaniale) (Legal 1994).

\footnotetext{
${ }^{3}$ Nous tenons à remercier Pierre Courtot, responsable départemental pour la Vendée, pour son accueil dans la forêt et l'octroi des autorisations nécessaires pour circuler dans l'espace domanial, ainsi que Cécile Dardignac et Sophie David, archéologues à l'ONF au siège de Fontainebleau, pour leurs conseils. 


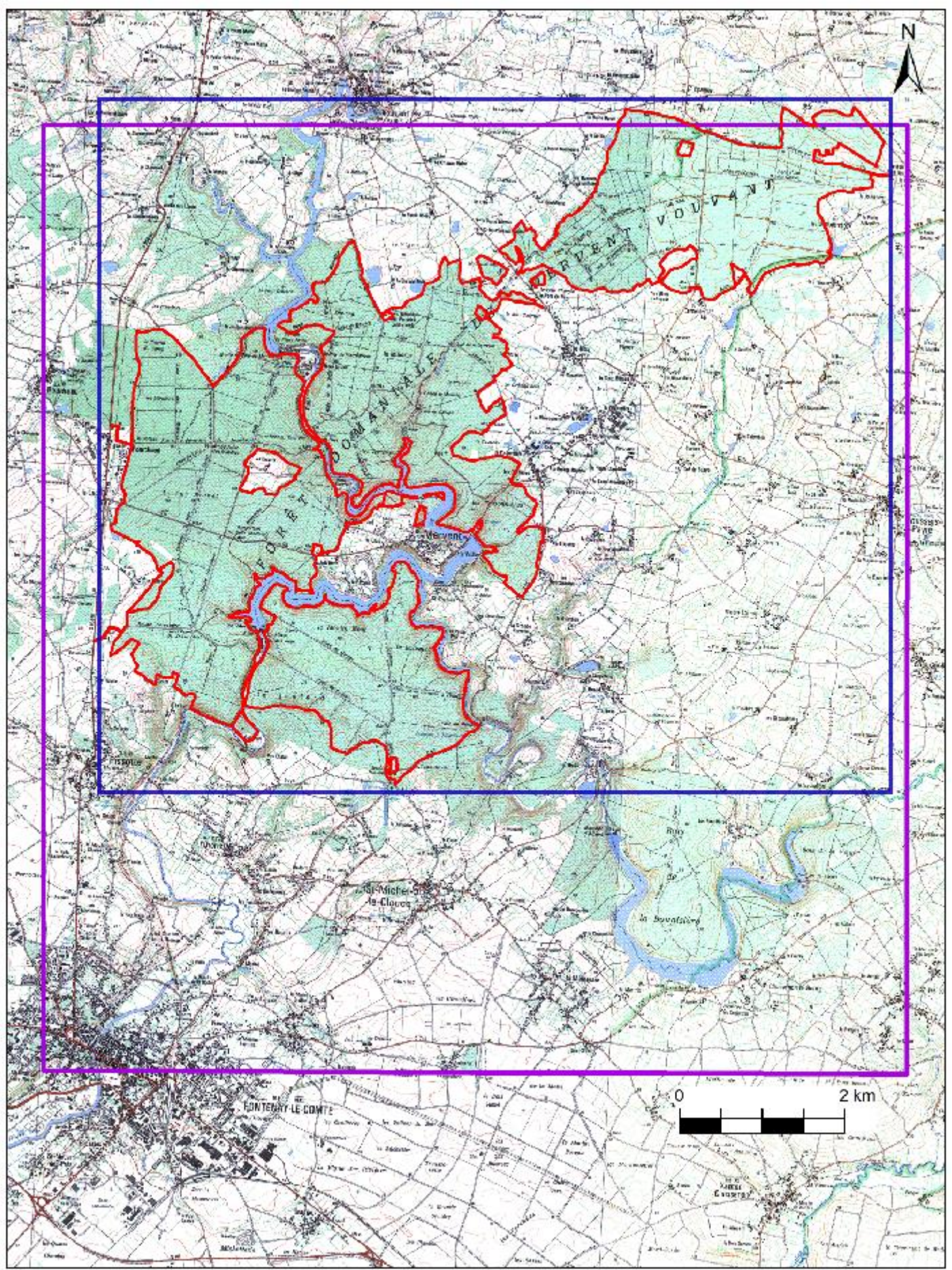

Fig. 4. Zone d'étude couverte par le LiDAR (en violet) et étendue de la forêt domaniale (en rouge). Le cadre intérieur (en bleu) localise le plan de 1788 (cf. fig. 6). Source : carte à 1/25 000 (@ IGN) et données de l'ONF.

L'originalité géologique du secteur est d'être localisé à cheval entre le socle du Massif armoricain (dans sa partie sud) et la bordure nord du bassin aquitanien (Petit et Tomczyk 2018) (fig. 5). Plus précisément, Mervent se situe sur un substrat d'orthogneiss interprété comme la matérialisation du prolongement de la branche méridionale de la suture sud-armoricaine. Il en résulte une topographie très vallonnée - qui fait tout le charme et les atouts touristiques de ce massif - alternant parfois avec des escarpements très marqués, hauteurs (max. $117 \mathrm{~m}$ ) et ruisseaux ou rivières encaissées et sinueuses dont les deux principales, la Mère et la Vendée, font confluence au pied du bourg de Mervent (fig. 2). Trois barrages ont créé des retenues d'eau qui élargissent ponctuellement le cours de ces rivières, faisant place à de grands plans d'eau. La végétation forestière est composée dans la partie domaniale principalement de chênes sessiles (65\%), exploités et vendus par l'ONF. Dans les parcelles forestières privées, le boisement est plus mixte et marqué par l'enrésinement. Quant aux boisements situés en bordure de la Mère, ils sont constitués de feuillus (frênes, aulnes, saules, peupleraies). Ce milieu 
accueille une flore et une faune reconnues comme particulièrement riches et exceptionnelles, qui justifient le classement du massif en ZNIEFF (Zone naturelle d'intérêt écologique, faunistique et floristique) de type II («grands ensembles naturels riches et peu modifiés, offrant des potentialités biologiques importantes ») et de 495 ha situés le long de la vallée de la Vendée en zone Natura $2000^{4}$. La forêt est aujourd'hui essentiellement dédiée au tourisme et aux loisirs (nombreux circuits pédestres, équestres et cyclables, bases de loisir, parc d'attractions, zoo...) ainsi qu'à l'exploitation du bois.

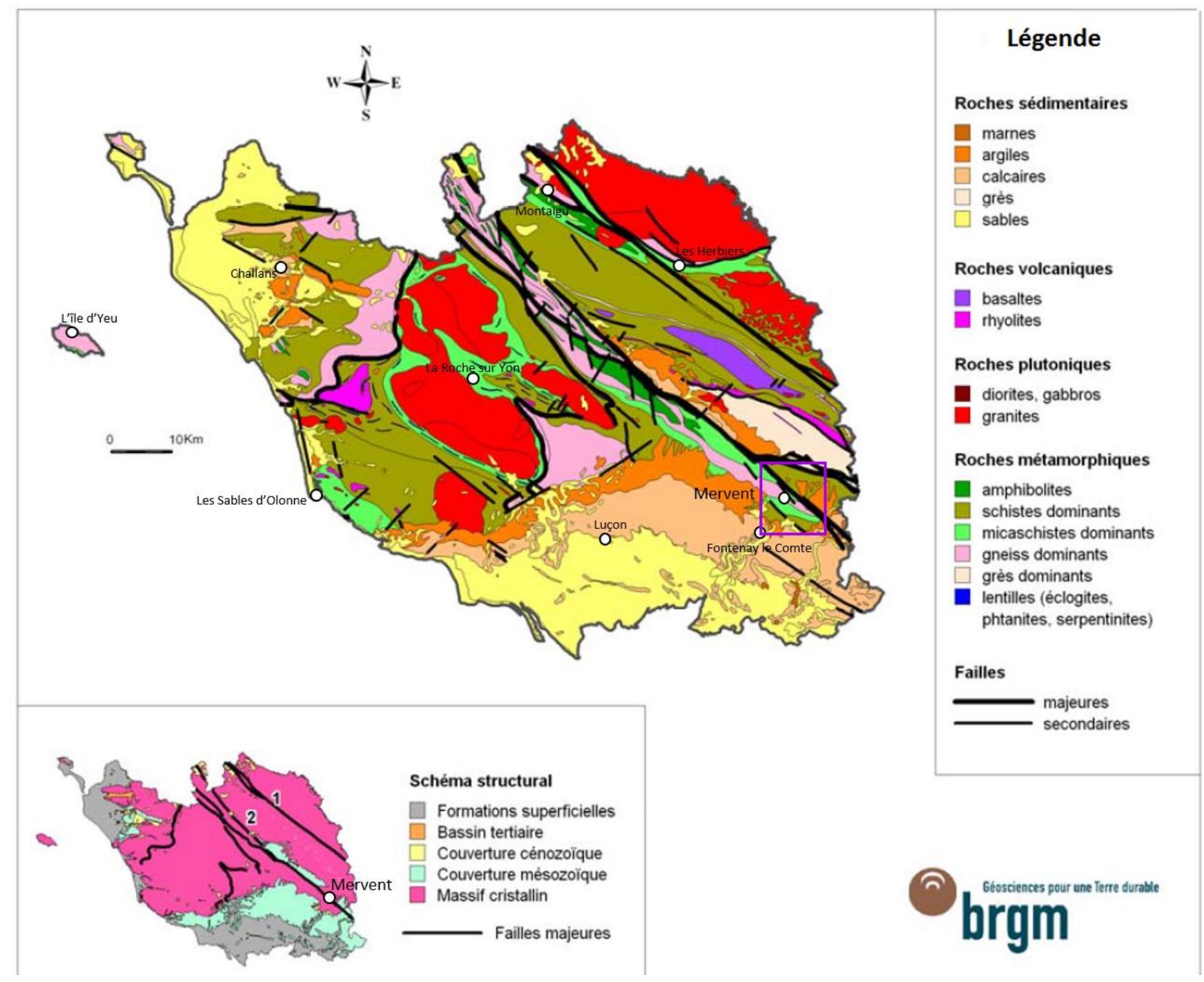

Fig. 5. Carte géologique simplifiée de la Vendée. Le cadre situé à l'est de Mervent (en violet) localise la zone d'étude du LiDAR présentée sur la fig. 4. (c) BRGM.

Le vol LiDAR réalisé pour le compte de la Direction régionale des affaires culturelles (DRAC) des Pays de la Loire le 20/01/2017 par GéoFit Expert ${ }^{5}$ a concerné 9300 ha comprenant la quasi-intégralité du massif forestier actuel, moins ses marges septentrionales autour de Vouvant. Cela couvre, partiellement ou entièrement, le territoire de onze communes ${ }^{6}$. La technique utilisée par l'entreprise a permis d'assurer une précision planimétrique et altimétrique de $3 \mathrm{~cm}$. Le tableau suivant présente le système de classification des points qui a été retenu. Le Modèle numérique de terrain (MNT) obtenu à partir des points classés dans la classe 2 («Sol») dispose d'une exactitude planimétrique et altimétrique de $0,10 \mathrm{~m}$ et $0,07 \mathrm{~m}$ et la grille ainsi constituée présente un pas de $50 \mathrm{~cm}$ de résolution

\footnotetext{
${ }^{4}$ Voir T. You et P. Rouillier (LPOVendée), P. Dulac (LPO85), "Massif forestier de Mervent-Vouvant et ses abords ", Inventaire national du patrimoine naturel, SPN-MNHN Paris, 84 p. [en ligne] https://inpn.mnhn.fr/zone/znieff/520005745.pdf

${ }^{5}$ Les méta-données du vol LiDAR ont été versées dans une base de données collective sur les couvertures LiDAR réalisées en France hébergée par la plateforme "Huma-Num ». Cette base de données est pilotée et gérée par l'ingénieur-géomaticien Laurent Costa (CNRS, MAE Nanterre). Cf. rapport rendu par GeoFIT expert dans Nillesse dir. 2018.

${ }^{6}$ Bourneau, Fontenay-le-Comte, Foussais-Payré, L'Orbrie, Mervent, Pissotte, Puy-de-Serre, Saint-Hilaire-des-Loges, Saint-Michel-leCloucq, Vouvant, Xanton-Chassenon. 
(fig. 1). Frédéric Melec (topographe à l'Inrap) a traité ce MNT selon différents azimuts et élévations pour créer des cartes sous Global Mapper ainsi que des vues en 3D et différents profils topographiques de sites. L'exploitation de cette mission LiDAR est encore en cours.

\begin{tabular}{|c|c|}
\hline Classes & Description \\
\hline $\mathbf{1}$ & Classe par défaut - Tous les points non classifiés \\
\hline $\mathbf{2}$ & Sol \\
\hline $\mathbf{7}$ & Points aberrants (points bas et points hauts) \\
\hline 12 & Cut Overlap [points redondants] \\
\hline
\end{tabular}

Tableau 1. Classification des points obtenus suite au relevé LiDAR. C GéoFit Expert 2017

En effet, la première année du PCR a surtout consisté à établir le corpus des indices connus et à faire un bilan très détaillé et critique des ressources bibliographiques existantes de façon à circonscrire leurs atouts et limites. Pour établir la «carte archéologique » précise du massif, la couverture LIDAR a bien sûr été exploitée, nous y reviendrons, mais d'autres données ont été exploitées, à commencer par les indices de sites répertoriés dans la Carte archéologique de la Vendée (Provost et al. 1996) et dans la base de données Patriarche gérée par le Service régional de l'archéologie (SRA) des Pays de la Loire. Cette première couche d'informations archéologiques comporte en particulier l'ensemble des sites recensés par l'archéologue départemental Émile Bernard en 1987 lors d'une prospection-inventaire sur huit communes du massif forestier (Bernard 1987). Elle a également été enrichie par les apports d'autres inventaires, plus spécifiques, comme celui de Guillaume Saint-Didier (2018) concernant la métallurgie du fer ou celui de Jean-Marc Large (2018) sur les découvertes mobilières datant du Paléolithique, du Néolithique et de l'âge du Bronze. Des prospections pédestres régulières sur le terrain ont permis d'identifier de nouveaux sites et/ou de préciser la nature de certains déjà connus. Par ailleurs, le dépouillement systématique de la bibliographie (plus de 90 références parues entre 1804 et 2017), en particulier ancienne ${ }^{7}$, a permis de documenter ces sites et d'en identifier d'autres. Pour le premier siècle couvert par ces recherches, le bilan est bien maigre. On dispose de très peu de documentation graphique, avec un seul plan de fouilles pour un four de verrier et une seule carte figurant des fortifications. Par ailleurs, le mobilier est très rarement conservé et est essentiellement constitué de pièces lithiques. Néanmoins, quelques rares objets sont figurés. Bon nombre de «sites» mentionnés dans les écrits des érudits anciens n'existent donc pas, ou plus. Néanmoins, et malgré ces réserves, on dispose d'un certain nombre d'éléments qui, rassemblés, soulignent le potentiel archéologique de la forêt de Mervent.

\footnotetext{
${ }^{7}$ L'aide indéfectible de Sophie Corson (Historial de la Vendée) doit être soulignée pour la recherche de la bibliographie ancienne, parfois confidentielle ou difficile d'accès; elle a été efficacement secondée par Ophélie Guinet (stage de Master 1, université de Nantes). 


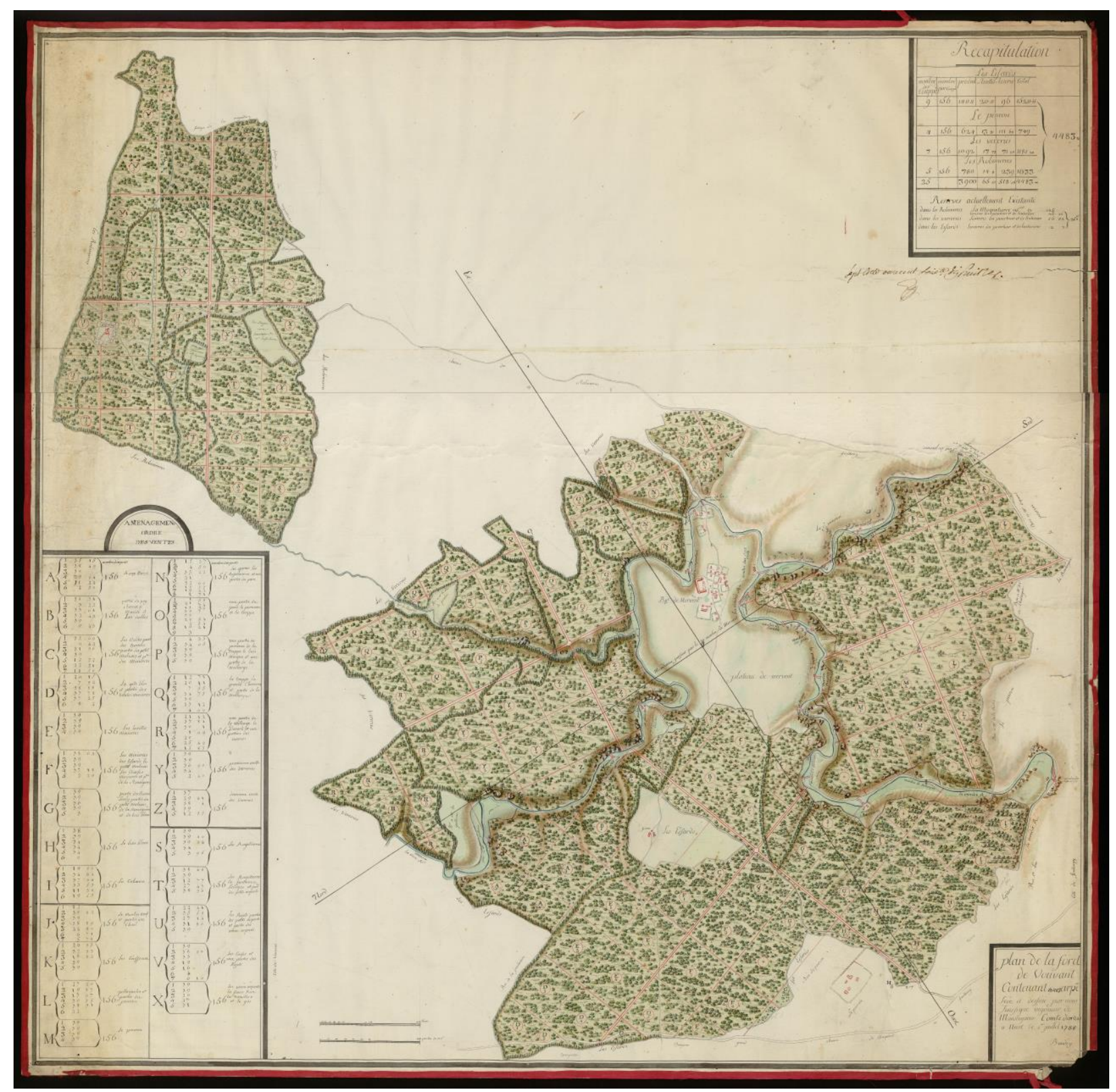

Fig. 6. Plan de la forêt de Vouvant contenant 4483 arpents levé et dessiné par nous soussigné ingénieur de monseigneur Comte dartoy a Niort le $1^{\text {er }}$ juillet 1788. Par Baudry, Niort, 1788. Éch. 1/9 800. La carte est localisée sur la fig. 4. Cote AN (département des Cartes et Plans) : N II Vendée 1. (C) AN.

La documentation planimétrique ancienne a également été réunie, dans le cadre d'une thèse d'archéogéographie soutenue en 2009 qui embrassait l'espace ici considéré (Watteaux 2009). Il faut mentionner un document exceptionnel, le Plan de la forêt de Vouvant contenant 4483 arpents levé et dessiné par nous soussigné ingénieur de monseigneur Comte dartoy a Niort le $1^{\text {er }}$ juillet 1788 , réalisé à Niort par un certain Baudry et conservé aux Archives nationales ${ }^{8}$ (fig. 6). Il figure la forêt de Mervent à une date relativement ancienne, avant les travaux de sylviculture entrepris au milieu du XIX $\mathrm{X}^{\mathrm{e}}$ siècle. Cependant, le parcellaire forestier figuré est en réalité - contrairement à ce que laisse entendre la légende - un projet d'aménagement qui n'a jamais été réalisé (rappelons que le plan date de $1788 \ldots$... ce que démontre l'analyse de la couverture LiDAR puisqu'on ne trouve pas dans la microtopographie les traces des limites forestières projetées sur le plan et que celles-ci ne correspondent pas à celles qui seront réifiées au XIX ${ }^{\mathrm{e}}$ siècle. C'est donc plutôt la représentation des contours du massif forestier, des chemins et de l'habitat qui nous intéresse dans ce document. Comme la carte de Cassini, les minutes au $40000^{\mathrm{e}}$ de la carte d'état-major et les plans du cadastre napoléonien, il a été géoréférencé et sert de base à l'étude archéogéographique en cours. Précisons que le cadastre ancien est disponible via le serveur cartographique régional GEOPAL. Il permet d'accéder aux versions les plus anciennes du

${ }^{8}$ Archives nationales (département des Cartes et plans), N II Vendée 1. Échelle : 1/9 800.

(C) 2020 ISTE OpenScience - Published by ISTE Ltd. London, UK - openscience.fr 
cadastre, dites planches du «cadastre primitif ». Il existe donc pour le secteur d'étude une mosaïque cadastrale très ancienne (à l'exception des communes de Bourneau et Vouvant, mais qui ne sont couvertes qu'en partie par le vol LiDAR), datant de 1809 à 1812. La vectorisation de l'ensemble du réseau routier qui y est figuré est en voie d'achèvement ${ }^{9}$, de même que la vectorisation intégrale de certains secteurs.

La cartographie contemporaine n'est évidemment pas en reste puisque l'objectif est de documenter les évolutions du massif forestier jusqu'à nos jours. Elle a également servi à faire le point sur les potentialités géologiques du massif, à partir de l'analyse approfondie de la carte géologique par Christophe Petit ${ }^{10}$ et Céline Tomczyk ${ }^{11}$ (Petit et Tomczyk 2018).

Un dernier mot, enfin, sur la documentation écrite ancienne. Elle ne fait pas l'objet d'une étude globale et systématique en soi, mais sera fortement mobilisée grâce aux études historiques ponctuelles déjà réalisées (en particulier Legal 1994 ; Markarian 1996 ; Canaud 2018) ou en cours (cf. infra).

\section{Inventaire et description des traces archéologiques reconnues}

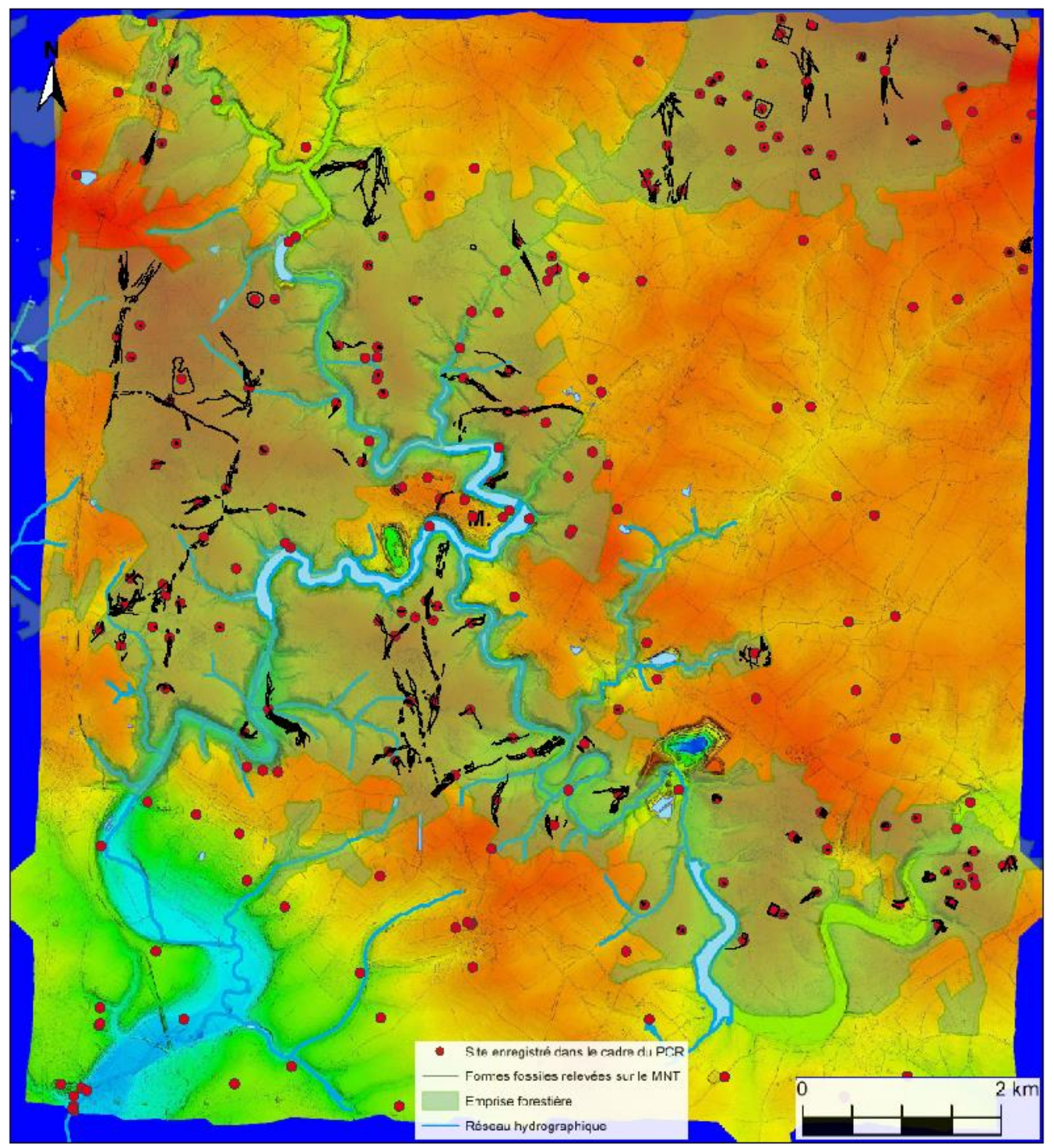

Fig. 7. Ensemble des indices reconnus à ce jour à partir du traitement du MNT, élévation $45 \mathrm{~m} / a z i m u t ~ 45^{\circ}$ (traces en noir sur point rouge) et des autres indices non visibles sur le LiDAR (points rouges seuls). Source : MNT/LiDAR, Nillesse dir. 2018, relevés : J.-M. Bryand, F. Melec, O. Nillesse.

\footnotetext{
${ }^{9}$ Opération réalisée pour toute la Vendée par Pascal Vialet et Christophe Collard (Inrap).

${ }^{10}$ Professeur d'archéologie environnementale, université Paris 1, UMR ArScAn/équipe « Archéologies environnementales ».

${ }^{11}$ Doctorante en géoarchéologie, université Paris 1, UMR ArScAn/équipe « Archéologies environnementales ». 
La vectorisation sous système d'information géographique (SIG) des traces archéologiques identifiées ${ }^{12}$ a été effectuée à partir du traitement du MNT selon une élévation de $45 \mathrm{~m}$ et un azimut de $45^{\circ}$ (fig. 7). Les anomalies topographiques sont de deux types. Les premières correspondent à des dépressions dans le sol comme des fossés, des fosses simples ou polylobées. Les secondes sont des élévations, des murs, des talus ou des buttes. Elles peuvent se combiner comme dans le cas d'un rempart et de son talus. Ces indices ont ensuite été croisés avec les autres données connues par ailleurs, ce qui a permis d'établir une liste provisoire de 268 sites ou indices de sites dont 146 repérés grâce au LiDAR. À partir de ce recensement, une typologie provisoire a été établie par grandes catégories générales qu'il reste bien sûr à affiner :

- Artisanat (atelier de verrier, minerai de fer, ferrier, un «amas de scories de fer » est signalé dans la littérature, charbonnière, carrière, production céramique, four).

- Habitat (habitat divers, habitat fortifié en terre et/ou bois, maison, «maison forte », château).

- Édifices religieux (mégalithe, édifice religieux, nécropole/cimetière).

- Édifices militaires.

- Sites signalés par du mobilier.

- Éléments de voirie et de parcellaire.

- Autres (enclos, buttes, etc.).

Tous ces sites sont décrits dans une table attributaire qui comporte des rubriques portant sur des informations géo-administratives, sur les différents systèmes d'enregistrement des sites (PCR, Patriarche, autres inventaires locaux), sur le type des sites mentionné dans ces inventaires, sur le niveau de confiance accordé à ces interprétations, sur la visibilité ou non du site sur le LiDAR, sur des éléments de datation, sur les sources exploitées, sur la bibliographie concernée et sur d'éventuelles remarques.

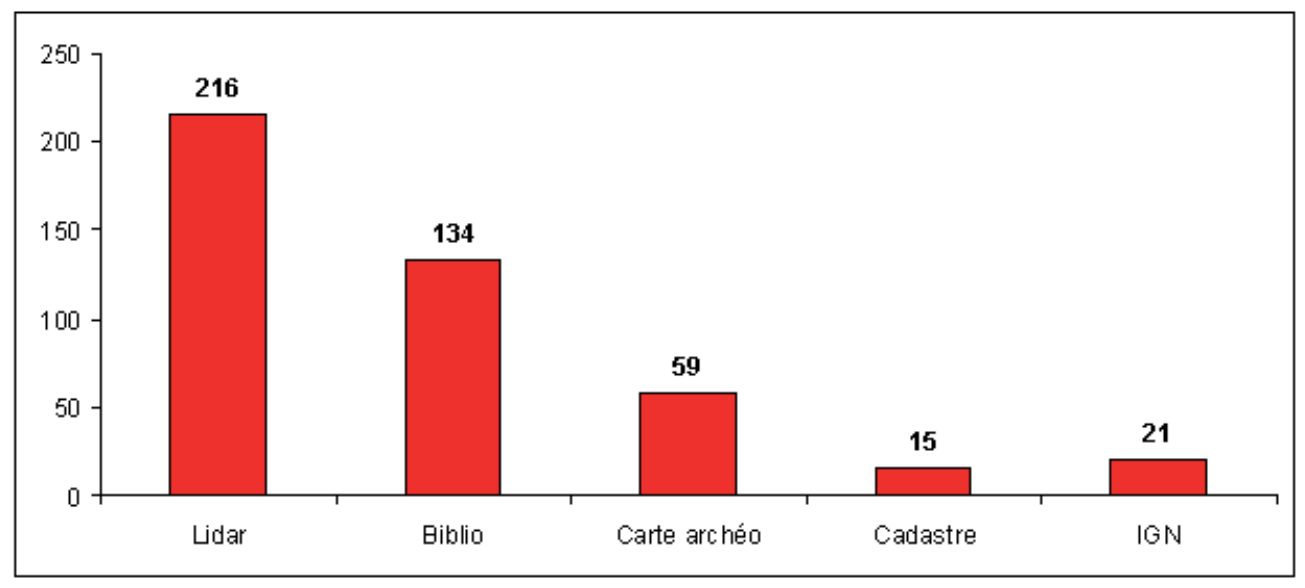

Fig. 8. Nombre d'indices par type de source. Source : Nillesse et al. 2018.

La carte archéologique du massif forestier de Mervent a pu être totalement et profondément renouvelée grâce à l'acquisition de la mission LiDAR. En effet, elle a permis de repérer 216 sites, dont 146 n'apparaissent que grâce à cette technique de détection (fig. 8). Ainsi, le LiDAR s'avère être la source contribuant le plus à l'inventaire archéologique : $65 \%$ des sites ou indices apparaissent sur la carte LiDAR alors que $40 \%$ sont connus par la bibliographie et seulement $18 \%$ par la Carte archéologique du SRA. Pour autant, tous les sites connus ne sont pas automatiquement visibles sur les images tirées du LiDAR. L'exemple des ferriers le rappelle: seuls ceux dont les élévations sont supérieures à $0,50 \mathrm{~m}$ sont visibles (exemple : fig. 9), alors que les ferriers étalés dans les pentes, détectés grâce aux plus grosses scories émergeant de l'humus, ne sont pas visibles sur les données

\footnotetext{
${ }^{12}$ Travail de vectorisation effectué par Jean-Marc Bryand (Inrap) sur la base des interprétations réalisées par Olivier Nillesse. 
LiDAR. Il faut également préciser que les anomalies topographiques de petites dimensions n'ont pas systématiquement été prospectées et qu'un certain nombre peuvent correspondre à ce type de vestiges.

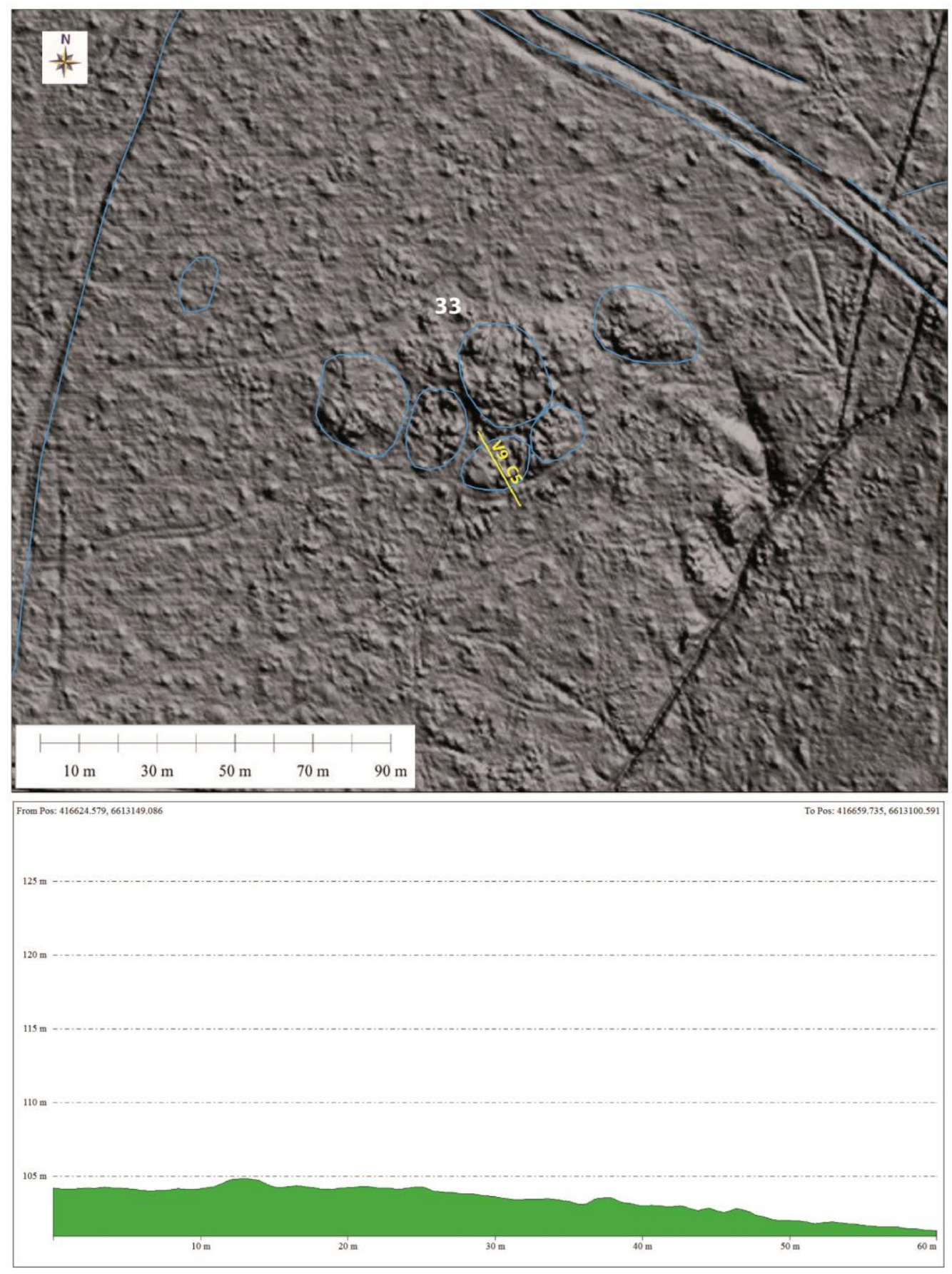

Fig. 9. Ferriers aux Guillotières (Puy-de-Serre, site $n^{\circ}$ 33). Source : MNT/LiDAR, relevés : J.-M. Bryand, F. Melec, O. Nillesse.

Certains sites ont pu être profondément réévalués après traitement du LiDAR. Par exemple, sur le site de hauteur de Berneveau (Saint-Michel-le-Cloucq) qui domine la rivière d'une quarantaine de mètres, les érudits du XIX ${ }^{\mathrm{e}}$ siècle avaient supposé l'existence d'un rempart qui a finalement été invalidée (fig. 10). Par contre, deux levées de terre sont apparues au nord, sur un second méandre. Les mesures réalisées sur le MNT (fig. 11) permettent de préciser que le premier rempart, au nord, s'étend sur une centaine de mètres, qu'il est rectiligne puis semble interrompu avant de reprendre vers le sud. Le fossé est large d'environ 3,60 m et le talus de $4 \mathrm{~m}$. La hauteur entre le fond du premier et le sommet du second n'est que de $0,70 \mathrm{~m}$. Dans sa largeur maximale, les deux éléments se développent sur une largeur de 7,70 m, qui pourrait être portée à $13,50 \mathrm{~m}$ si l'on considère qu'il existe les vestiges d'une rampe sur le côté sud. Le second rempart est reconnu sur environ $80 \mathrm{~m}$. Son fossé est large de 3,50 m, la largeur du talus est plus difficile à déterminer, mais elle se situe aux alentours de $10 \mathrm{~m}$. La hauteur 
entre le fond du premier et le sommet du second n'est que de $1 \mathrm{~m}$. Les dimensions de ces remparts apparaissent donc assez modestes, mais il faut rappeler qu'avant sa fouille, celles de l'ouvrage du Chêne Tord l'étaient encore plus (le fossé était totalement comblé et les restes du rempart calciné se distinguaient à peine au sol). La surface enclose est inférieure à 12 ha. Reste maintenant, et ce n'est pas la moindre des difficultés, à en comprendre la chronologie et la fonction...
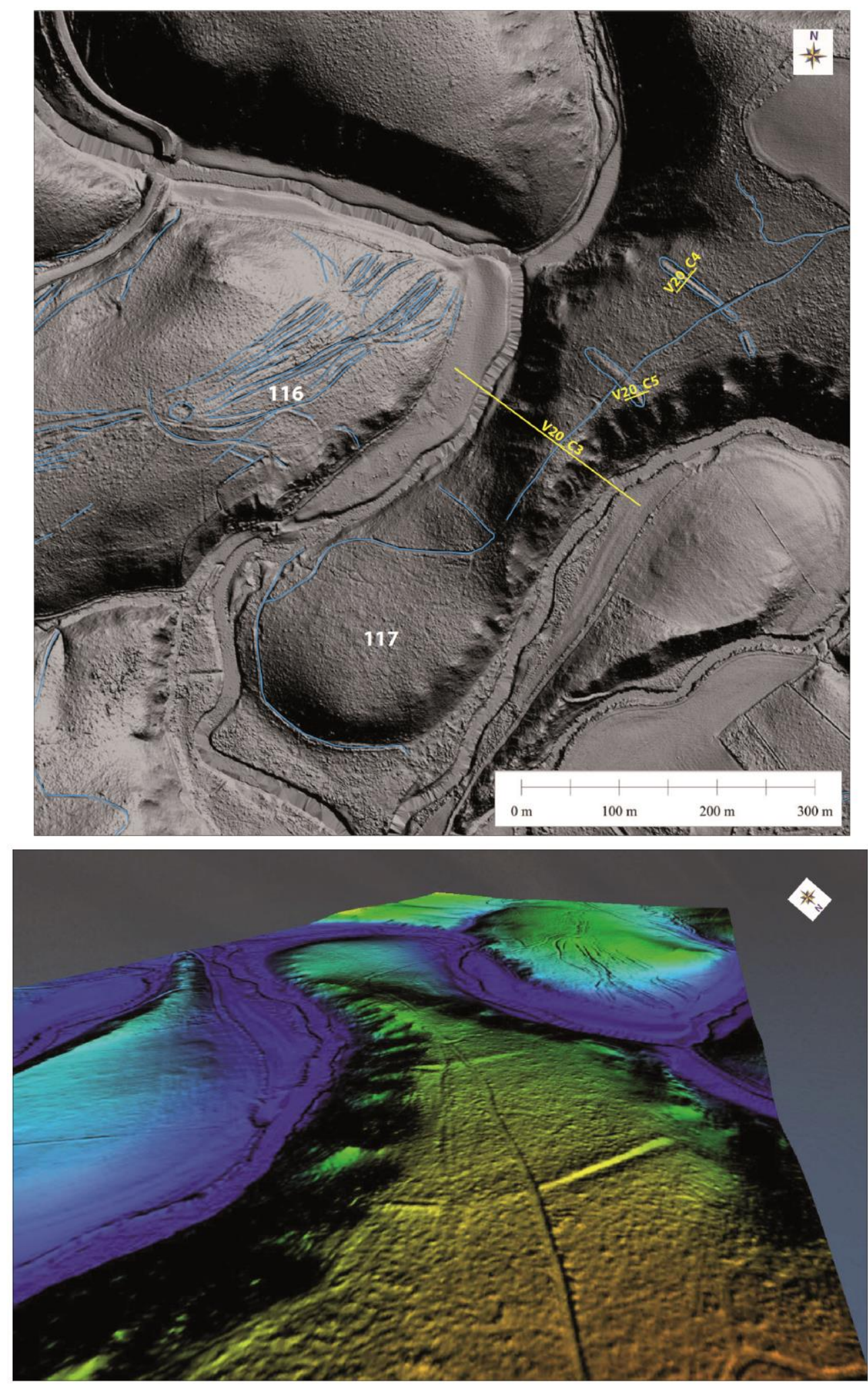

Fig. 10. Le site de hauteur fortifié de Berneveau (Saint-Michel-le-Cloucq, site $n^{\circ} 117$ ). Source : MNT/LiDAR, relevés : J.-M. Bryand, F. Melec, O. Nillesse. 

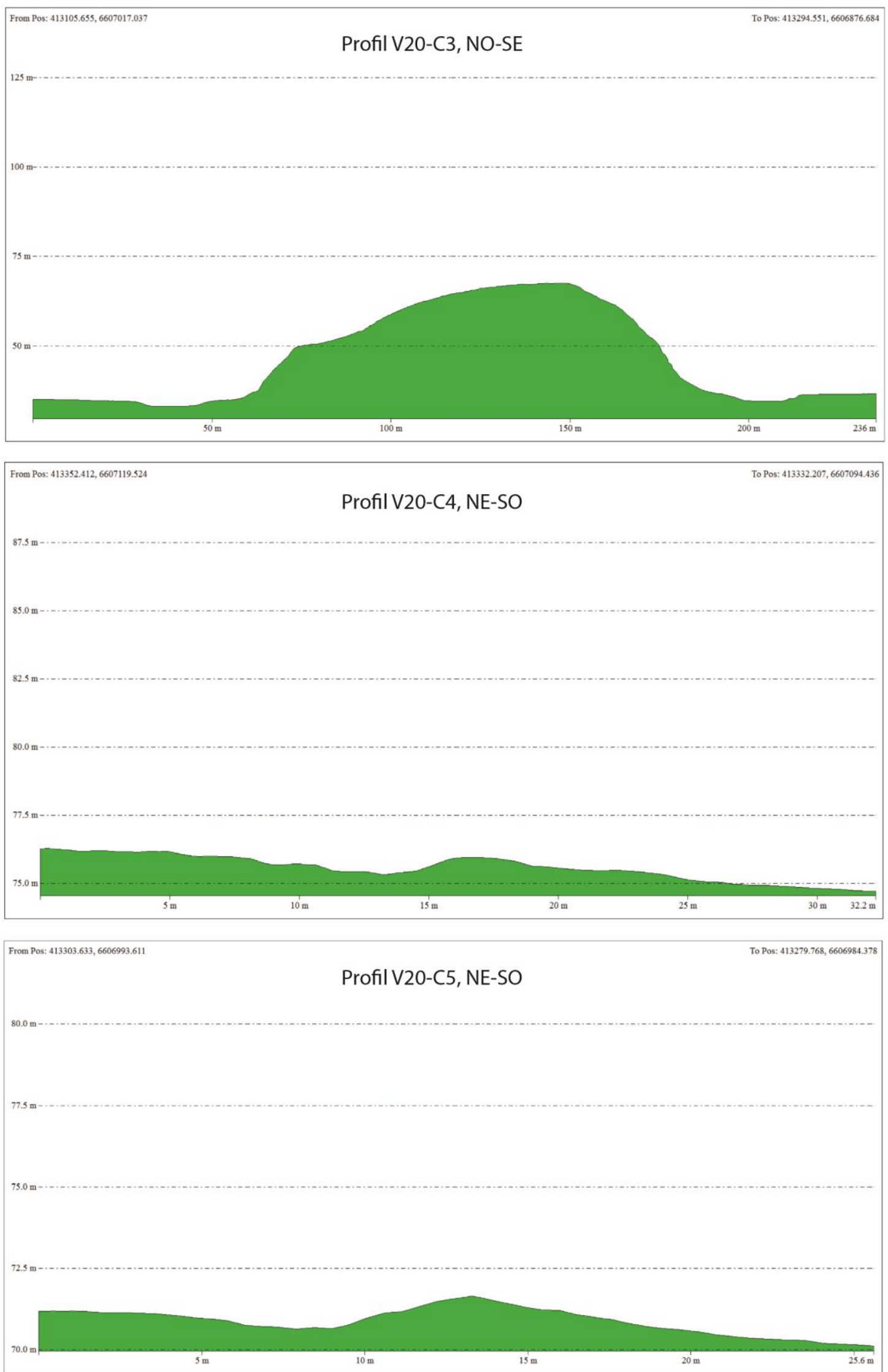

Fig. 11. Profils du site de Berneveau (Saint-Michel-le-Cloucq, site $n^{\circ} 117$ ). Source : MNT/LiDAR, relevés : J.M. Bryand, F. Melec, O. Nillesse.

Le corpus établi comprend donc des sites ou indices de sites très hétérogènes, à tous points de vue, $\mathrm{y}$ compris des sites non localisés comme les douze mégalithes susmentionnés. Ce pré-inventaire sera donc à reprendre en 2020, certaines interprétations devant être revues (précisées ou modifiées). Par ailleurs, le nombre de sites le sera nécessairement aussi. En effet, des ferriers que nous avons détaillés un par un devront être regroupés dans un seul atelier, et certains systèmes viaires devront être 
regroupés dans le même réseau ou au contraire divisés en plusieurs branches. Enfin et surtout, l'inventaire des traces repérées à partir des données LiDAR n'a été réalisé, nous l'avons dit, que selon un seul azimut (45) et une seule altitude (45). Il reste donc à traiter dix autres versions du document selon ces deux paramètres $(0 / 15 ; 90 / 15 ; 180 / 15 ; 270 / 15 ; 90 / 45 ; 135 / 45 ; 180 / 45 ; 225 / 45 ; 270 / 45$; $315 / 45$ ) afin d'apporter des compléments pour certains sites et d'en découvrir d'autres.

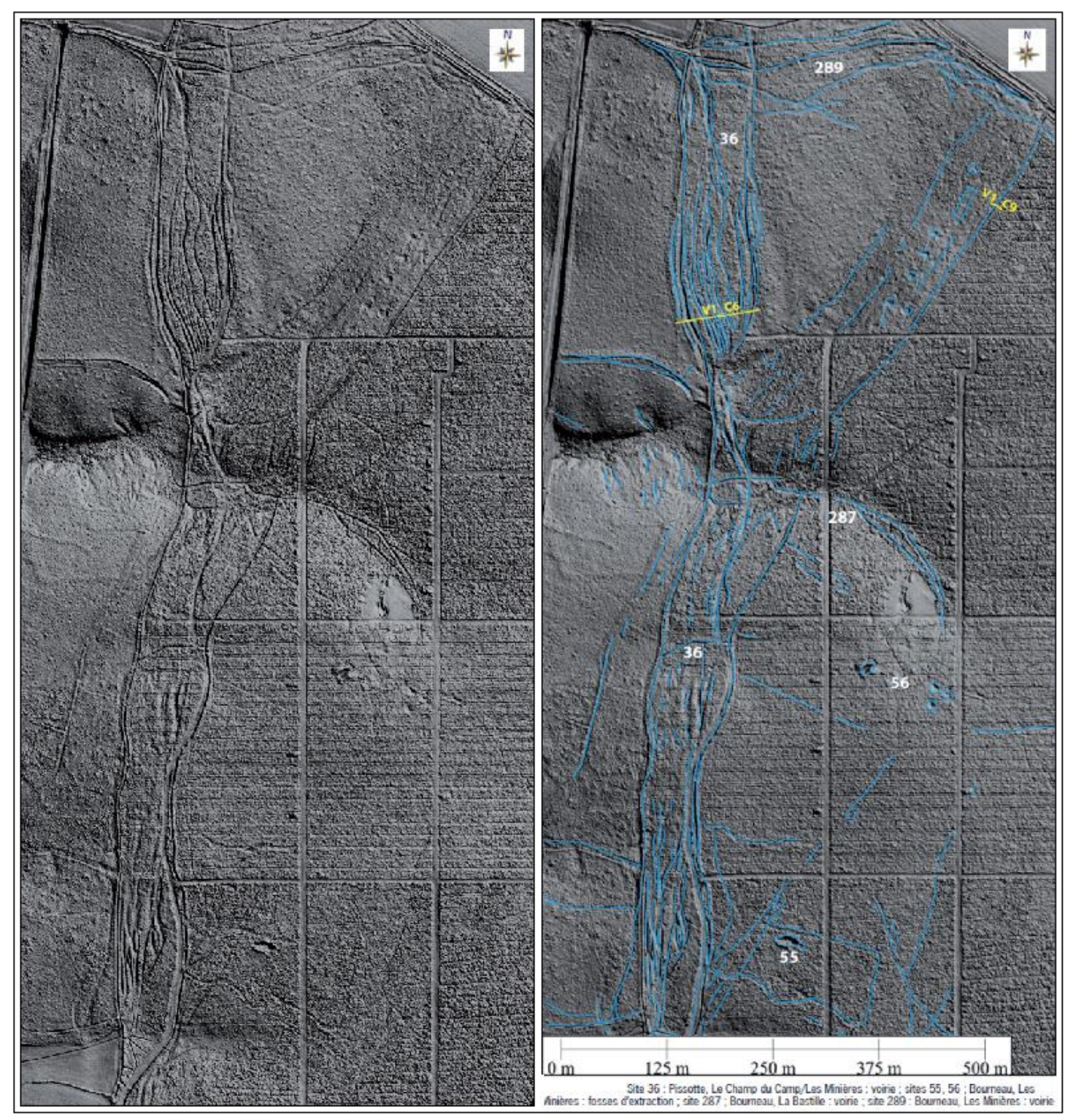

Fig. 12. Formes fossiles linéaires observées aux Minières (Pissotte et Bourneau, site $\left.n^{\circ} 36\right)$. Source: MNT/LiDAR, relevés : J.-M. Bryand, F. Melec, O. Nillesse.

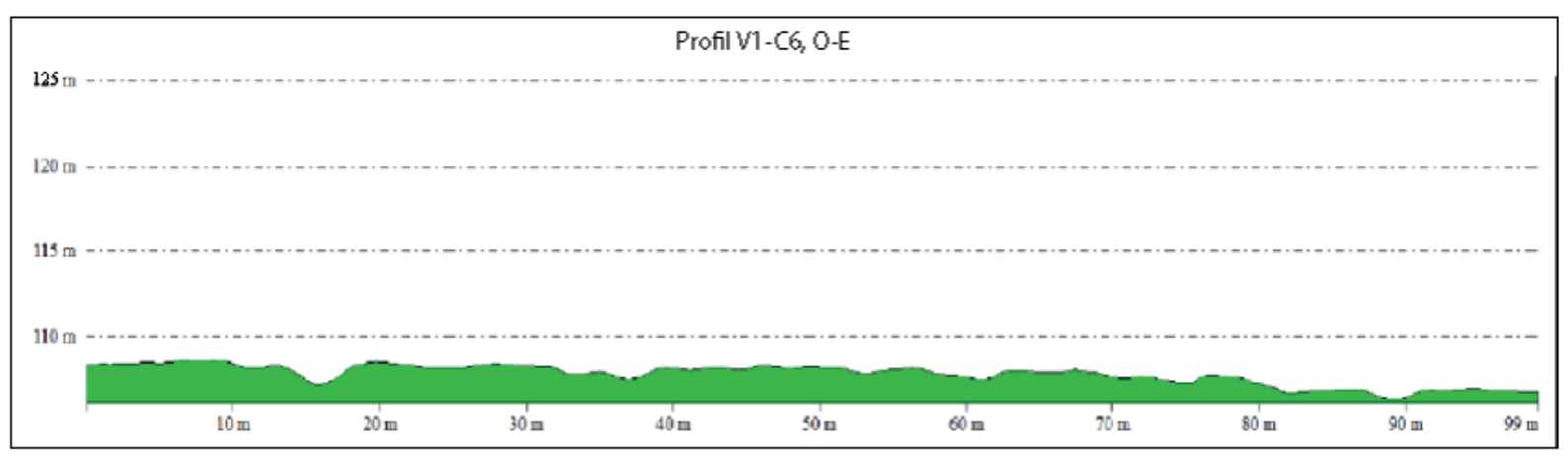

Fig. 13. Profil du site des Minières (Pissotte et Bourneau, site $n^{\circ}$ 36). Source : MNT/LiDAR. Relevés J.-M. Bryand, F. Melec, O. Nillesse. 
Enfin, certaines traces ne sont pas encore bien comprises. C'est le cas en particulier pour un ensemble d'indices linéaires classés initialement dans la rubrique «Éléments de voirie », mais dont l'interprétation n'est pas encore cernée. Ces traces, nombreuses, présentent une morphologie en patted'oie en bas des pentes et dont l'interprétation pose parfois problème. Sur le terrain, on trouve de nombreuses structures de ce type, le LiDAR ayant permis de bien les caractériser. Certaines ont un profil en « $\mathrm{V}$ » et sont profondes de $2 \mathrm{~m}$ pour une largeur de $5 \mathrm{~m}$, mettant en question l'hypothèse a priori évidente de réseaux de chemins. Prenons le cas emblématique du site des Minières à Bourneau (fig. 12 et 13). Là, une série de lignes très incisées se calquent sur un réseau viaire visible sur la carte IGN à 1/25 000 et sur le plan de la forêt de 1788 . Ceci étant, si certaines traces correspondent bien à des chemins creux (larges et plats), il est plus difficile d'interpréter un certain nombre comme étant des chemins qui, par définition, doivent être empruntés pour circuler. Car, et c'est là tout le problème, l'exiguïté de certaines de ces structures à fond très étroit (fig. 14) limite sévèrement les possibilités de circulation : à pied, cela est difficile (l'expérience a été menée!) et c'est encore moins envisageable avec un cheval ou un bœuf et a fortiori avec un véhicule tracté. On ne peut pas objecter que ces structures soient érodées, car un processus de dégradation aurait conduit à des profils non pas en « $\mathrm{V}$ » mais adoucis, en forme de cuvette. Il faut souligner également que l'action naturelle de l'eau ne peut être mise en avant pour expliquer leur présence dans des terrains drainants. Enfin, dans le cas de systèmes viaires, il est difficile de comprendre les motivations qui auraient conduit leurs instigateurs à créer de nouveaux cheminements par des creusements synonymes d'un investissement important alors qu'ils se situent juste à côté des précédents. Ainsi, pour le site $\mathrm{n}^{\mathrm{O}} 111$ au Jaulard (L'Orbrie), sur plus de $100 \mathrm{~m}$ de large, on observe pas moins de 15 tracés différents, se croisant parfois, qui ne sont pas tous dus au piétinement vu leur impact au sol (fig. 15 et 16).
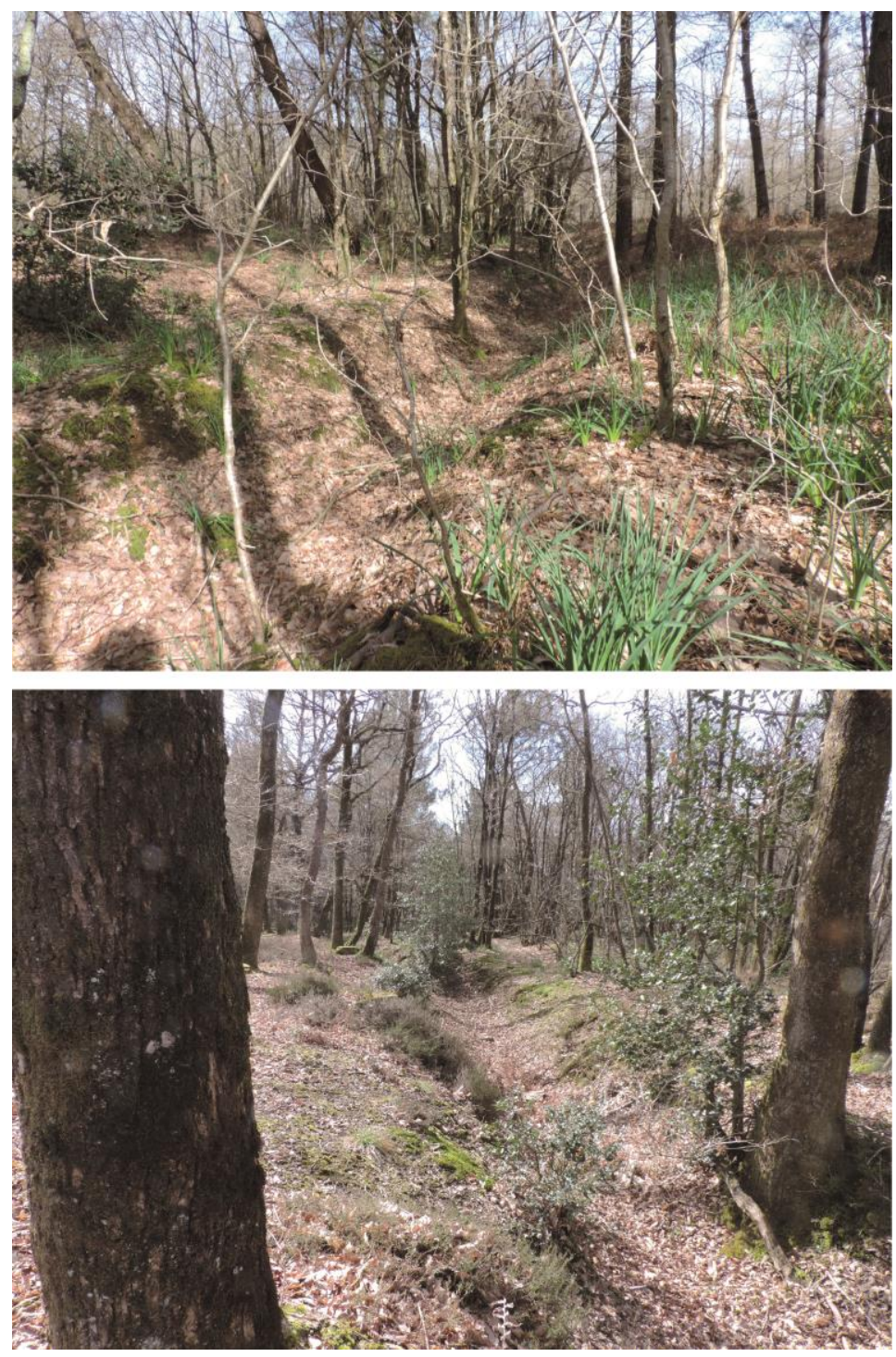

Fig. 14. Creusements linéaires (Champ du Camp/Les Minières, site $n^{\circ}$ 36). Cliché : Olivier Nillesse, 2018. 


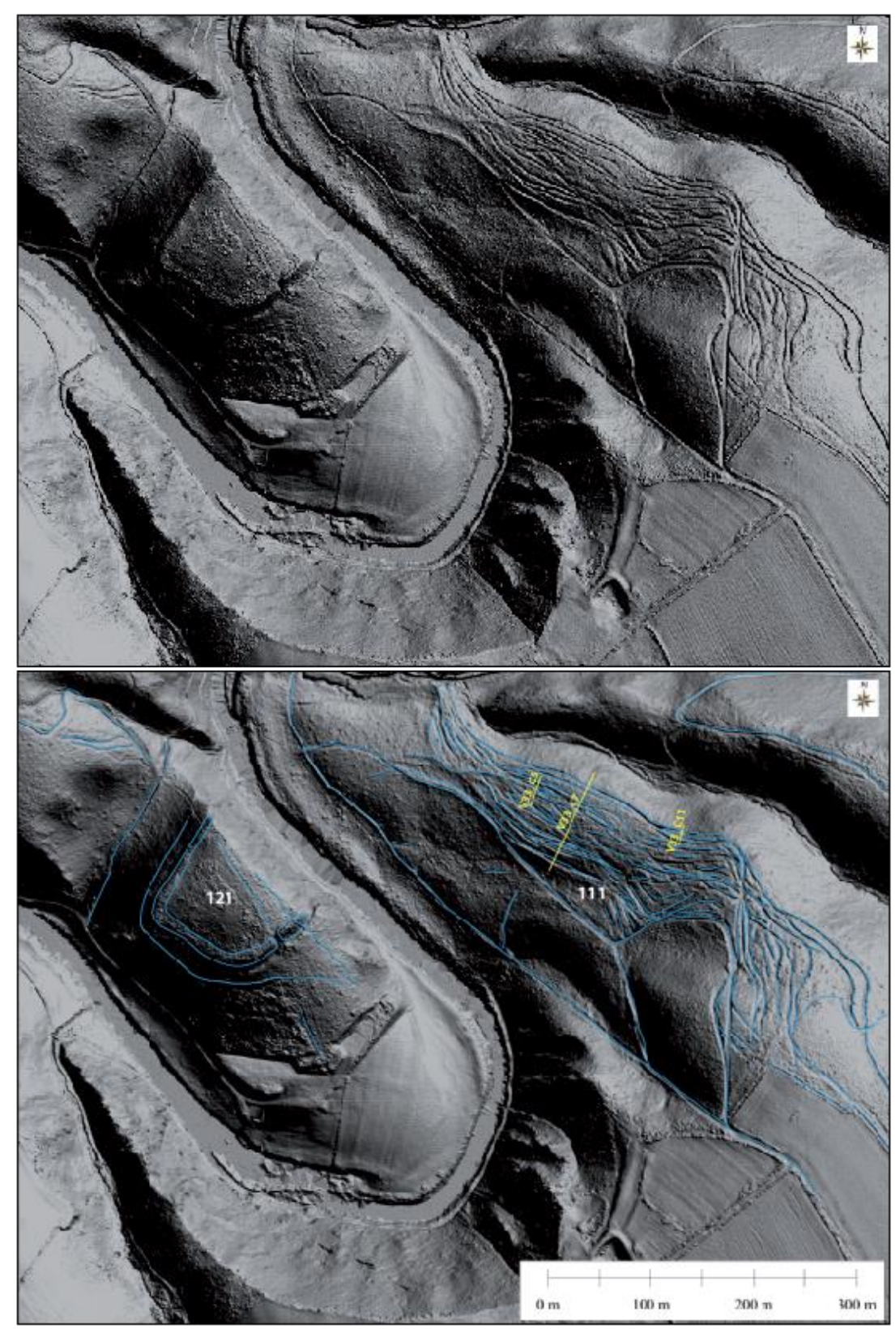

Fig. 15. Formes fossiles linéaires observées au Jaulard (L'Orbrie, site $\left.n^{\circ} 111\right)$. Source: MNT/LiDAR, relevés : J.-M. Bryand, F. Melec, O. Nillesse.

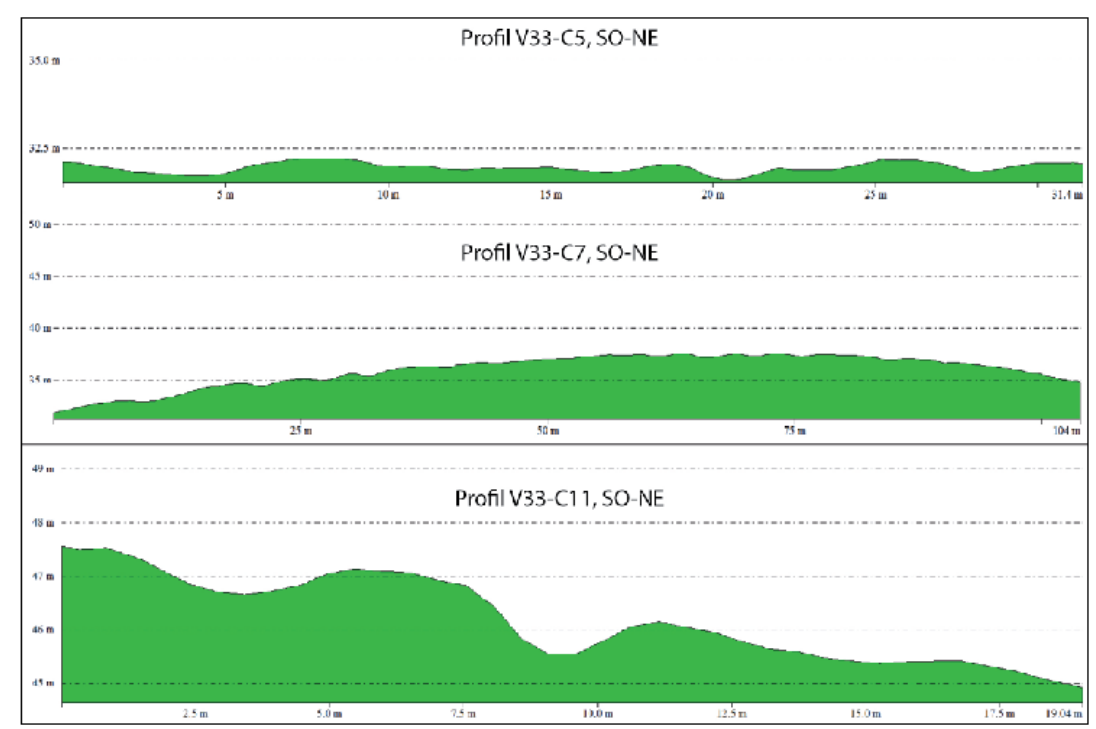

Fig. 16. Profil du site du Jaulard (L'Orbrie, site $n^{\circ}$ 111). Source : MNT/LiDAR, relevés : J.-M. Bryand, F. Melec, O. Nillesse. 
L'hypothèse de «tranchées d'extraction » creusées pour rechercher des pisolites ferrugineuses ou de l'argile a donc été posée pour tenter d'éclaircir le sens de ces structures. Des gisements riches en pisolites sont attestés à l'est de la zone d'étude, mais dans des zones non boisées qui ne sont pas concernées par la détection LiDAR. Guillaume Saint-Didier (2017) fait mention de telles tranchées dans sa thèse, mais il précise également que d'autres tranchées peuvent correspondre à des carrières d'argile. En effet, le plus souvent, les argiles où sont localisées ces «minières » sont pauvres en pisolites ferrugineuses. Christophe Petit et Céline Tomczyk (2018) notent d'ailleurs, sur une zone test (fig. 17), qu'à côté des formations schisteuses décrites sur la carte géologique, il est possible que la formation 25 (arènes, argiles), propice à une exploitation d'argile, n'ait pas été cartographiée par les géologues. S'agissant de l'exploitation sidérurgique, les deux géoarchéologues concluent à l'absence de gisements majeurs de minerai de fer là où l'on trouve ces creusements linéaires énigmatiques. Pour résumer, ces «tranchées d'extraction» n'ont vraisemblablement pas été creusées pour rechercher du minerai de fer, qui d'ailleurs ne se présente pas sous la forme de filons quand il s'agit de pisolites. L'hypothèse de carrières d'argile semble également assez fragile, cette matière première s'exploitant sous la forme de fosses plus ou moins importantes dans certains secteurs de la forêt, une extraction linéaire ne présentant aucun avantage particulier. Depuis 2019, c'est donc plutôt sur la piste d'une éventuelle extraction d'étain que se poursuit l'enquête (cf. infra).

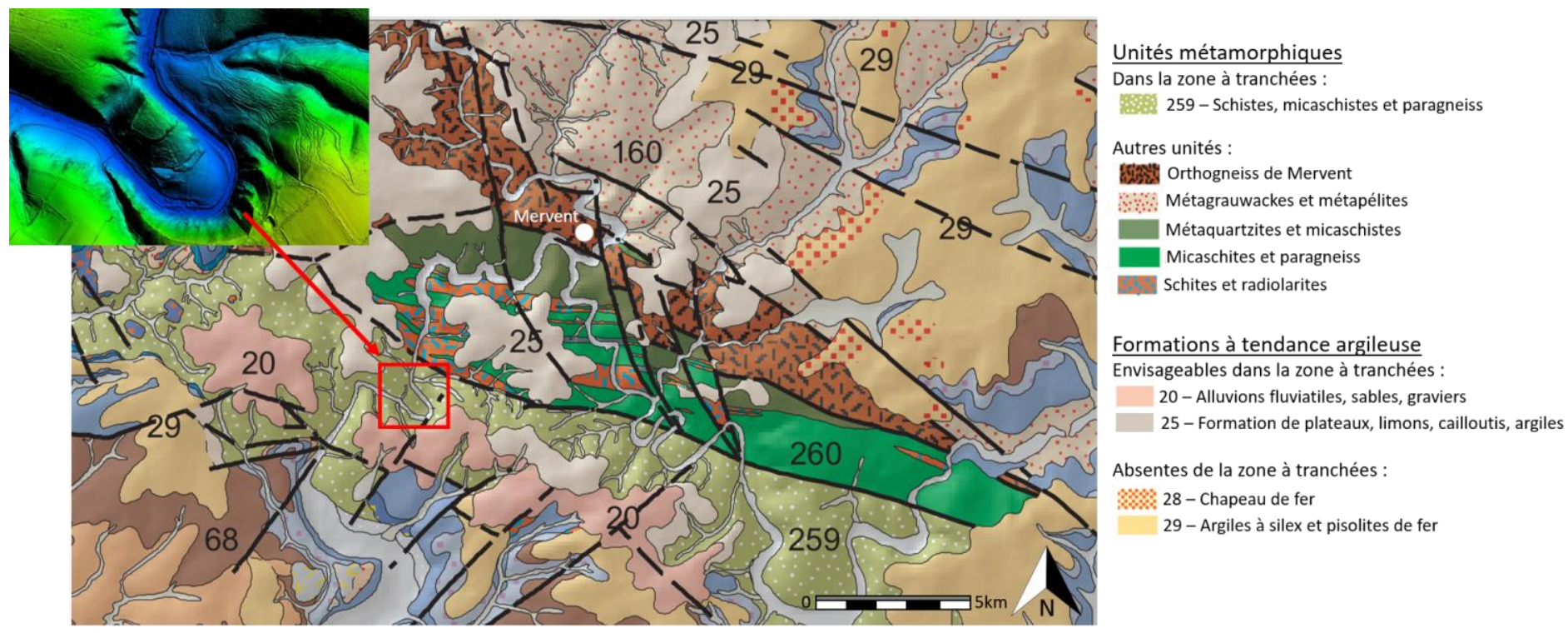

Fig. 17. Analyse géologique des potentialités d'extraction en argile et en pisolites ferrugineuses. Dans la possible zone d'exploitation d'argile, des formations schisteuses sont décrites, mais il y a une probabilité de trouver les formations 20 et 25 qui n'auraient pas été cartographiées. La formation 29 (à pisolites de fer) est associée aux formations jurassiques (en bleu) et ne peut donc pas affleurer dans la zone en question. La formation 20 est de type détritique et ne présente que des passes argileuses : elle est inadéquate pour une exploitation à grande échelle. La formation 25 pourrait tout à fait s'y prêter. Source : Petit et Tomczyk 2018.

En conclusion, le caractère provisoire de ce corpus invite à considérer avec prudence les premiers éléments de datation. Ainsi, sur les $31 \%$ de sites qui ont pu être datés (fig. 18), l'importance de certaines périodes doit être relativisée, comme la Préhistoire qui n'est signalée que par du mobilier hors contexte et des mégalithes disparus. On note également que le premier âge du Fer ressort de cet inventaire comme étant le parent pauvre du corpus avec le seul site de Mervent, alors que le PCR a été bâti au départ pour donner un contexte à cette agglomération fortifiée... ! L'étude sera donc plus que jamais diachronique. 


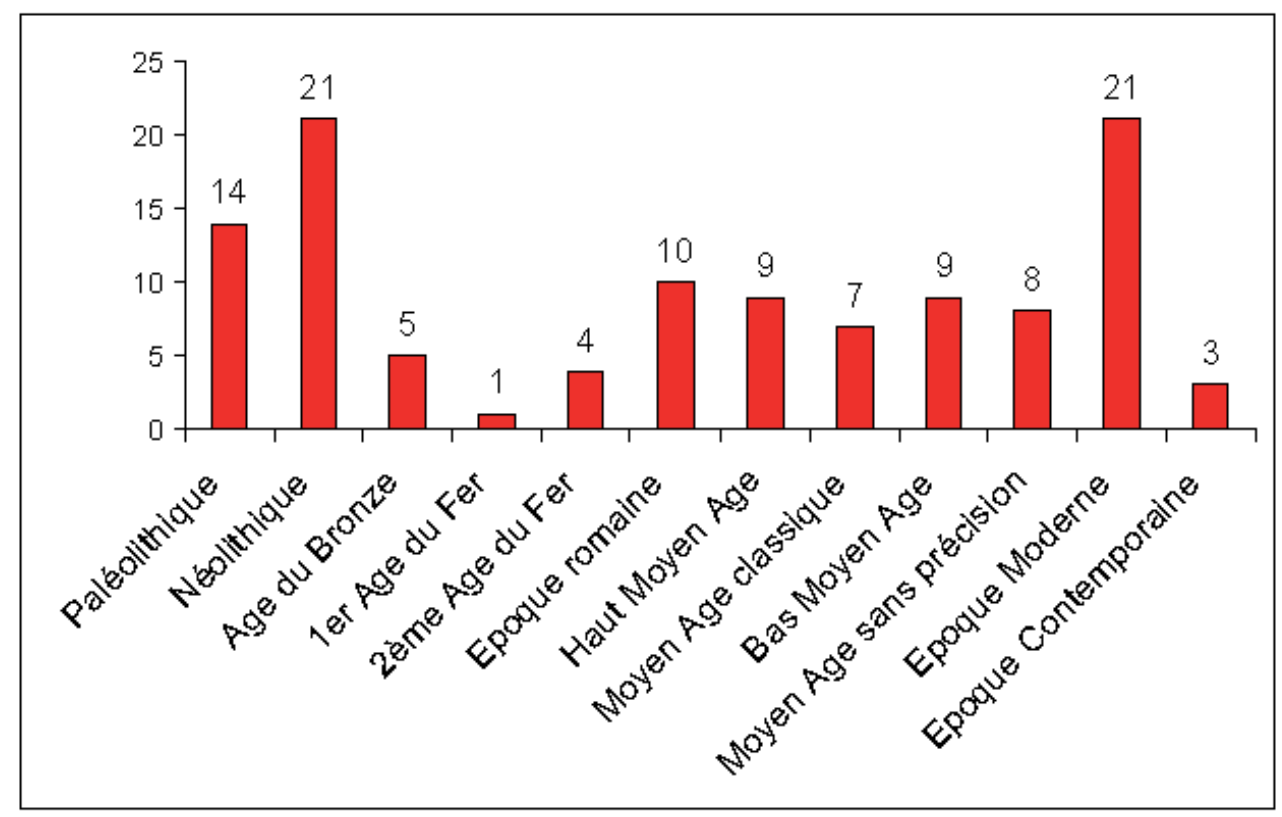

Fig. 18. Nombre de sites par phase chronologique. Source : Nillesse dir. 2018.

\section{Premières analyses et perspectives de recherche}

À l'issue des deux premières années de recherche, les deux questions principales qui ont motivé le PCR n'ont pas trouvé de réponses. Les pistes concernant une activité d'extraction et de réduction du minerai de fer durant la Protohistoire, qui expliquerait les ressources et activités des habitants de l'agglomération fortifiée de Mervent à cette époque, n'ont pu être confirmées. En effet, la datation des indices métallurgiques est rarement établie et surtout les méthodes de production du fer attestées (scories coulées) ne correspondent majoritairement pas à celles utilisées durant la Protohistoire, caractérisées par des fours à scories piégées. Il semble qu'aucun ferrier de plusieurs milliers de mètres cube de déchets, tels qu'on en connaît à Archigny dans la Vienne avec des volumes compris entre 1000 et $5000 \mathrm{~m}^{3}$ (Saint-Didier 2017) n'ait existé dans le massif forestier. L'esquisse d'un modèle d'organisation des habitats fortifiés est pour l'instant une gageure dans la mesure où les éléments de datation les concernant sont faibles, inexistants ou douteux, sauf évidemment pour les fouilles récentes au Chêne Tord. Il serait donc nécessaire de réaliser des sondages pour établir leur datation et des prospections géophysiques pour préciser la nature des occupations. Par ailleurs, le début d'enquête sur la fortification du Saint-Luc montre surtout des occupations médiévales non négligeables (cf. infra). Cette évolution de la recherche a conduit à nous rapprocher de médiévistes et à reconsidérer le projet sous un angle beaucoup plus diachronique, la Protohistoire étant devenue par la force des choses le parent pauvre de ce projet. La place de l'analyse archéogéographique de cet espace a donc augmenté en conséquence (Watteaux 2018).

Les perspectives de recherche aujourd'hui dessinées sont au nombre de cinq.

- L'extraction d'étain durant la Protohistoire. Tout d'abord, l'enquête sur une éventuelle extraction d'étain durant la Protohistoire dans les fameuses tranchées suivant les pentes évoquées supra doit se poursuivre. En 2019, Céline Tomczyk a réalisé quelques batées (reconnaissance de fragments de minerais d'étain par maniement d'une batée en rivière), mais qui n'ont malheureusement pas permis de confirmer l'interprétation espérée. De nouveaux prélèvements seront réalisés en 2020, plus en aval de ces tranchées, car le potentiel de concentration de cassitérite y est plus élevé.

- Habitat et exploitation des ressources naturelles au Moyen Âge. S'agissant des périodes médiévale et moderne, l'exploitation approfondie et critique de la bibliographie ancienne a permis de revaloriser les étapes médiévales de l'occupation du sol sur le massif forestier, qu'il reste à mieux documenter grâce à des recherches en archives. On sait déjà qu'une importante nécropole du très haut Moyen Âge sur le promontoire du Saint-Luc (fig. 19) précède l'installation d'un prieuré mentionné en 
1656 (en l'état du dépouillement des sources archivistiques) et dépendant de celui de Fors dans les Deux-Sèvres $^{13}$. Le site de hauteur du Sauvaget qui lui fait face aurait pu accueillir un ermitage (et probablement pas un habitat vu la difficulté d'accès du plateau), matérialisé par un enclos fossoyé sur trois côtés et enserrant un espace d'un peu plus d'un hectare (fig. 20). Plusieurs microtoponymes comportant le mot «ermite» sont connus dans la forêt à l'époque moderne ${ }^{14}$, en raison du caractère parfois très reculé de certaines parties de la forêt. C'est du moins une hypothèse à tester en dépouillant la documentation écrite dans les centres d'archives. Il conviendra également de faire le point sur le couvent des Robinières à Puy-de-Serre, bien visible sur les données LiDAR et qui ne dispose pas à ce jour de synthèse. L'aide de l'historien médiéviste Cédric Jeanneau (université de Brest), spécialiste du second Moyen Âge en Bas-Poitou, a été sollicitée pour ce faire.

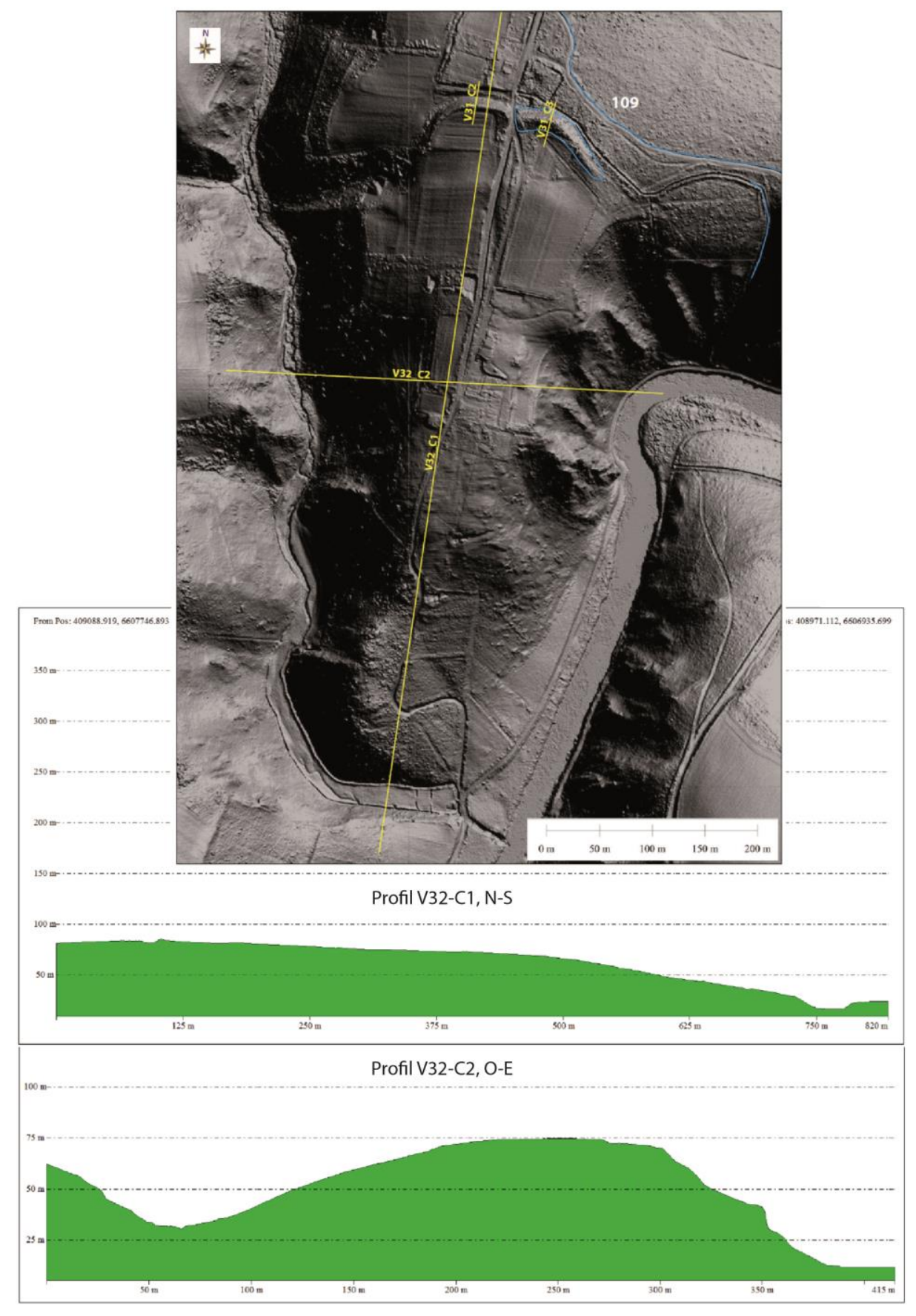

Fig. 19. Le promontoire du Saint-Luc et son rempart à ailes rentrantes (Pissotte, site $n^{\circ}$ 108). Source : MNT/LiDAR, relevés : J.-M. Bryand, F. Melec, O. Nillesse.

\footnotetext{
${ }^{13}$ Archives départementales de la Vendée, 1 NUM 47/147.

${ }^{14}$ Le plus célèbre fut l'ermite Louis-Marie Grignon de Montfort, retiré dans une " grotte » de la forêt en 1715 . Bien qu'il y restât très peu (chassé pour avoir abattu des arbres de la forêt royale sans autorisation !), un pèlerinage populaire s'est développé après sa mort (1716) à cet endroit, encore vivace de nos jours. 


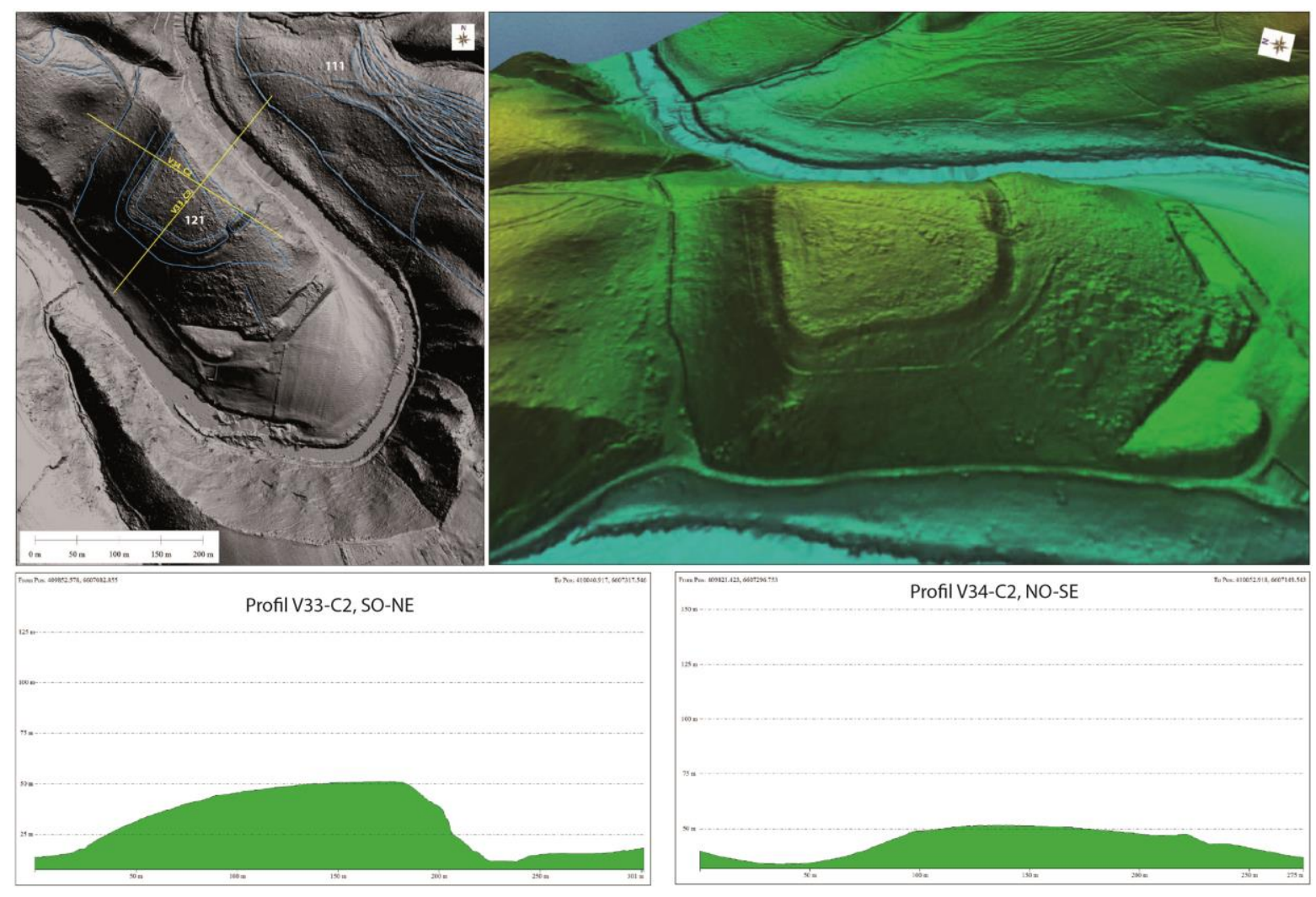

Fig. 20. Le promontoire de Sauvaget fermé par un rempart sur trois côtés, le quatrième étant naturellement défendu par une falaise de près de $40 \mathrm{~m}$ de hauteur (Pissotte, site $n^{\circ} 121$ ). Source : MNT/LiDAR, relevés : J.M. Bryand, F. Melec, O. Nillesse.

- Dans l'immédiat, deux travaux de recherche font avancer le PCR sur ces périodes, dans le cadre d'un Master 1 et d'un Master 2 actuellement réalisés par deux étudiants de Rennes 2, respectivement sur l'artisanat du verre et de la terre (de l'extraction aux productions) par Étienne Nicol, et sur le château de Mervent par Valentin de Filippo. Le premier se fonde sur un état des lieux prometteur réalisé en 2018 par Alain Champagne ${ }^{15}$ dans le cadre de la première année du PCR (Champagne 2018). Ces travaux doivent prolonger les premières pistes en exploitant la bibliographie ancienne des érudits vendéens, les résultats de la prospection-inventaire de 1987 sur les ateliers de verriers, les microtoponymes évocateurs de ces artisanats et les indices de sites reconnus sur la couverture LiDAR. Le massif de Mervent s'avère en particulier très intéressant pour la problématique de la production verrière, car de nombreux toponymes ou microtoponymes s'y rapportent et 11 indices de sites sont identifiés comme tels, voire ont été fouillés depuis le XIX ${ }^{\mathrm{e}}$ siècle. Émile Bernard (1990) a fouillé en particulier un atelier de verriers daté du $\mathrm{XIV}^{\mathrm{e}}$ siècle aux Petites Verreries à Vouvant, découvert à l'occasion de la vidange du barrage de Mervent. Les sources écrites témoignent également de cette activité dès le XIV ${ }^{\mathrm{e}}$ siècle. S'agissant de l'artisanat de terre, outre quelques toponymes évocateurs, les sources écrites regorgent de mentions de tuiliers ou marchands tuiliers $d u X^{e}$ au $X^{\mathrm{e}} \mathrm{X}^{\mathrm{e}}$ siècle dans le secteur, essentiellement pour approvisionner le marché de la ville voisine de Fontenay-le-Comte. Soixante-cinq structures repérables sur les données LiDAR semblent liées à une activité d'extraction pour la construction, mais aussi pour la fabrication de chaux et le prélèvement d'argile. On sait justement par la documentation écrite que durant le Moyen Âge et l'époque moderne la production de chaux était associée à celle des terres cuites architecturales. La cartographie des structures d'extraction sur un fond géologique est donc à réaliser.

- L'autre recherche de Master consiste à faire le point sur nos connaissances sur le château de Mervent, dont quelques ruines surplombent de manière aussi impressionnante que romantique le cours de la Mère et dont les douves ont été partiellement explorées lors des fouilles préventives menées en 2012 (Nillesse dir. 2012). Son histoire est indissociable de celle du château de Vouvant, situé juste au nord du massif forestier (et malheureusement hors emprise du LiDAR), tenu pendant longtemps par les

\footnotetext{
${ }^{15}$ MCF en histoire et archéologie médiévales, université de Pau et des pays de l'Adour, EA 3002 ITEM. 
mêmes seigneurs (les Lusignan) et d'implantation topographique similaire (éperon barré surplombant un méandre de la même rivière, la Mère) (Canaud 2018). Ces deux sites, comtaux et ducaux déjà durant la première moitié du $\mathrm{XI}^{\mathrm{e}}$ siècle, voient leur histoire intrinsèquement liée à celle du massif forestier. Mervent est en effet initialement une résidence de chasse utilisée par les comtes de Poitou-Ducs d'Aquitaine. On sait par les textes qu'ils s'installent à l'emplacement d'une ancienne viguerie et délèguent leur pouvoir à un châtelain. La question de l'étendue de la forêt de Mervent à cette époque est donc essentielle, car elle constitue une clé de lecture majeure du site castral et de son environnement.

- Histoire de la forêt et des parcellaires sous forêt. Une étude régressive de l'emprise de la forêt de Mervent devra donc être conduite afin de cerner au mieux les fluctuations de son étendue. Par ailleurs, cette forêt possède un parcellaire aux formes régulières caractéristiques des aménagements forestiers modernes qui masque l'organisation ancienne de cet espace. On sait par l'analyse du cadastre napoléonien que ces quadrillages datent du milieu du $\mathrm{XIX}^{\mathrm{e}}$ siècle, ce qui est particulièrement récent pour un massif de cette importance. Par ailleurs, sous la forêt et en total décalage avec le maillage forestier récent, certaines limites parcellaires ressortent, dont il conviendra de faire l'analyse morphologique et de tenter de comprendre la chronologie. Au vu des premières lectures des données LiDAR, il ne ressort pas un nombre très important de ces limites, contrairement à ce qui a pu être observé dans d'autres massifs forestiers où une large part de la forêt recouvre des parcellaires romains et médiévaux étendus comme dans la forêt de Haye en Lorraine ou dans la forêt du Châtillonnais en Bourgogne. Il faut rappeler que nous sommes ici dans un contexte topographique et géologique très différent des forêts de plaine mentionnées. Se pose donc la question de l'ancienneté de la forêt de Mervent, en tant que forêt, et du degré de mise en valeur agricole de certains de ses secteurs. Le fait que le sous-sol ne soit a priori pas propice à l'exploitation agricole ne doit pas empêcher de se poser la question car, outre des clairières ponctuelles dont la réalité est d'ores et déjà attestée, des exemples existent qui montrent une mise en culture de terres acides peu compatibles avec un usage agricole (cf. exemple inédit sur le massif de Fontainebleau, voir David à paraître).

- Circulations en forêt de Mervent. La précision du LiDAR a fait apparaître des kilomètres de chemins ou sentiers toujours empruntés ou fossilisés : 92 ensembles viaires ont été vectorisés. Le nombre très important de ces chemins - qui semble a priori plus important que dans les autres massifs forestiers ayant fait l'objet de survols LiDAR - pose la question des logiques de circulation dans cet espace. Celui-ci semble très parcouru et la forêt apparaît comme un espace qui est tout sauf ignoré ou évité. Il conviendra donc d'étudier sur les cartes anciennes et les données LiDAR l'ensemble de ce dense chevelu afin de comprendre ce que ces chemins reliaient et desservaient, et les raisons pour lesquelles ils sont si nombreux et si proches les uns des autres. Pour cela, le croisement avec la carte archéologique de la forêt sera indispensable, de même que l'étude de leur matérialité (profondeur, profil). Il conviendra également de restituer le niveau d'eau ancien des rivières de la Mère et de la Vendée qui traversent l'espace considéré. On sait en effet que onze gués ont été noyés depuis la création du barrage de Mervent en 1956. Une attention particulière sera portée aux relations entre les sites de hauteur (fortifiés ou non).

- Analyse micro-régionale : la forêt de Mervent dans l'ensemble paysager sud-vendéen. La problématique des circulations comme celle de la mise en culture de certains espaces aujourd'hui boisés amènent à s'interroger sur les liens existant entre le massif forestier de Mervent et les deux autres entités paysagères voisines : la plaine d'openfield et le bocage (ou semi-bocage) qui se déploie hors de cette plaine. C'est là un champ de recherche du point de vue archéogéographique en croisant les résultats de l'étude des circulations et de l'occupation du sol. Il sera ensuite intéressant de regarder comment ces relations changent ou se perpétuent durant les périodes antique, médiévale et moderne. L'incorporation d'une grande partie de la forêt de Mervent au domaine royal en 1694 marque une étape dans cette histoire qui contribue probablement à fermer cet espace; c'est là une autre hypothèse qu'il conviendra d'étudier, en s'aidant des travaux des historiens. 


\section{Conclusion}

Il est difficile de conclure de manière satisfaisante tant les pistes de recherche sont encore à peine empruntées... Nous avons voulu ici montrer le potentiel d'étude de cette enquête et la contribution majeure que représente la mission LiDAR pour l'établissement de la carte archéologique et, partant, pour la définition des problématiques de recherche. Les autres dossiers réunis dans ce numéro de NUMEAR, plus avancés, représentent à cet égard autant de points de comparaison utiles pour cerner l'originalité géographique et historique de ce massif forestier, et de sources d'inspiration sur le plan méthodologique.

\section{Bibliographie}

BERNARD, É. 1987. "Inventaire archéologique et prospection diachronique dans le massif forestier de MerventVouvant», Rapport de prospection-inventaire. Fontenay-le-Comte, Conservation départementale des musées de la Vendée.

BERNARD, É. 1990. «Un four de verrier dans la forêt de Vouvant », Annuaire départemental de la Société d'Émulation de la Vendée : 15-19.

CANAUD, É. 2018. «Le castrum de Vouvant», mémoire de Master 1 sous la dir. de N. Prouteau. Université de Poitiers, 2 vol.

Champagne, A. 2018. «Les artisanats du feu dans le secteur de la forêt de Mervent du Moyen Âge au XIX ${ }^{\mathrm{e}}$ siècle : état des lieux », in: O. Nillesse (dir.), «Recherches sur l'occupation du massif de Mervent (Vendée) et ses habitats fortifiés », rapport de PCR. Fontenay-le-Comte : 149-152.

DAVID, S. à paraître. «L'apport des données LIDAR à la connaissance d'un territoire: le massif forestier de Fontainebleau (Seine-et-Marne et Essonne) », Revue archéologique d'Île-de-France, à paraître.

LARGE, J.-M. 2018. «Une première approche de la préhistoire de la forêt de Mervent: compilation des données connues », in: O. Nillesse (dir.), «Recherches sur l'occupation du massif de Mervent (Vendée) et ses habitats fortifiés », rapport de PCR. Fontenay-le-Comte : 179-191.

LEGAL, P.-Y. 1994. «Bois et forêts en Bas-Poitou, XVIII ${ }^{\mathrm{e}}$ siècle. Contribution à l'histoire forestière et sociale », thèse de doctorat en histoire du droit. Université de Nantes, 2 vol.

Markarian, Ph. 1996. "La châtellenie de Fontenay-le-Comte au $X V^{\mathrm{e}}$ siècle », mémoire de maîtrise sous la direction de J.-L. Sarrazin. Université de Nantes, 1996.

NILLESSE, O. (DIR.). 2012. «Diagnostic archéologique rue des Douves (Mervent, Vendée)», Rapport final d'opération. Cesson-Sévigné, Inrap Grand-Ouest.

NiLleSSE, O. et al. 2014 «L'agglomération fortifiée de hauteur de la fin du Premier âge du Fer de Mervent (Vendée) et la typo-chronologie de la céramique du Premier âge du Fer dans les Pays-de-la-Loire et les Deux-Sèvres », Aquitania XXX : 61-102.

NiLLESSE, O. et al. 2017. «L'agglomération fortifiée de hauteur de la fin du Premier âge du Fer de Mervent (Vendée), le rempart du Chêne Tord», Aquitania, XXXIII : 7-34.

NiLLESSE, O. (DIR.). 2018. «Recherches sur l'occupation du Massif de Mervent (Vendée) et ses habitats fortifiés », rapport de PCR. Fontenay-le-Comte.

Petit, Ch. et C. TomczyK. 2018. «Mervent, premier aperçu géologique », in: O. Nillesse (dir.), «Recherches sur l'occupation du massif de Mervent (Vendée) et ses habitats fortifiés », rapport de PCR. Fontenay-le-Comte : 160-165.

Provost, M. et al. 1996. La Vendée, 85. Candé, Carte archéologique de la Gaule.

SAINT-DIDIER, G. 2017. La métallurgie du fer dans le Poitou. Extraction, réduction, forgeage (III siècle av. J.-C.-XV siècle). Rennes, PUR.

SAINT-DIDIER, G. 2018. «Extraction et métallurgie du fer», in: O. Nillesse (dir.), «Recherches sur l'occupation du massif de Mervent (Vendée) et ses habitats fortifiés », rapport de PCR. Fontenay-le-Comte : 153-159.

Watteaux, M. 2009. «La dynamique de la planimétrie et des réseaux routiers en Vendée méridionale. Études historiographiques et recherches archéogéographiques », thèse de doctorat sous la dir. de G. Chouquer. Université Paris 1, http://tel.archives-ouvertes.fr/tel-00421955/fr/ 
WatteauX, M. 2018. «Projet d'étude archéogéographique de la forêt de Mervent-Vouvant, campagne 2018, rapport d'activité », in: O. Nillesse (dir.), «Recherches sur l'occupation du massif de Mervent (Vendée) et ses habitats fortifiés », rapport de PCR. Fontenay-le-Comte : 166-178. 